\title{
LA ECONOMÍA POLÍTICA DEL CONOCIMIENTO JURÍDICO // Daniel
}

Bonilla $^{1}$

\section{Palabras clave}

derecho comparado / conocimiento jurídico / economía política

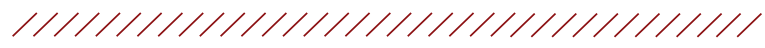

\section{Sumario}

1 Introducción

2 El libre mercado de las ideas jurídicas

2.1 El sujeto de conocimiento

2.2 El tiempo

2.3 El espacio

2.4 Las reglas y principios

3 El modelo colonial de producción, intercambio y uso de conocimiento jurídico

3.1 El sujeto de conocimiento

3.2 El tiempo

3.3 El espacio

$4 \quad$ Las reglas y principios

4.1 Las oposiciones conceptuales generales

4.2 Las oposiciones conceptuales particulares

5 Conclusión

6 Referencias

\section{Resumen}

La producción, intercambio y uso del conocimiento jurídico están sometidos a una economía política. Estos procesos están regidos por una serie de reglas y principios que determinan las condiciones de posibilidad para la creación, comercio y consumo de teoría, dogmática y prácticas jurídicas. Esta economía política, consecuentemente, no es neutral. Construye un sujeto de conocimiento específico que actúa dentro de un espacio y un tiempo particulares. Este escrito, por tanto, tiene un doble objetivo. Por un lado, busca describir y analizar el modelo de economía política que domina la imaginación jurídica contemporánea. En esta medida, busca examinar la estructura conceptual de lo que quisiera llamar el modelo del libre mercado de las ideas jurídicas. Por el otro lado, busca describir y analizar un modelo de economía política alternativo y periférico que explicaría de mejor manera las dinámicas reales que regulan la generación, tráfico y uso del conocimiento jurídico. Para conseguir este objetivo, el escrito hace explícitas las estructuras conceptuales que conforman el que quisiera llamar el modelo colonial de producción de conocimiento jurídico. El artículo, por ende, tiene como fin hacer explícitos los tipos de sujeto de producción de conocimiento jurídico al que los modelos dan lugar, así como la manera como imaginan el tiempo y el espacio en el que estos sujeto se sitúan. De igual forma, busca hacer explícitas las reglas y principios más precisos que determinan la manera como estos modelos imaginan la producción, intercambio y uso del saber legal. 


\section{THE POLITICAL ECONOMY OF LEGAL KNOWLEDGE // Daniel Bonilla}

\section{Keywords}

comparative law / legal knowledge / political economy

HIIIIIIIIIIIIIIIIIIIIIIIIIIIIIIIII

\begin{abstract}
The production, exchange and use of legal knowledge are subject to a political economy. These processes are governed by a series of rules and principles that determine the conditions allowing the creation, commerce and consumption of legal theories, doctrines and practices. Consequently, this political economy is not neutral; it constructs a specific subject of knowledge that acts within a particular space and time. Thus, this paper has two objectives. Firstly, it seeks to describe and analyze the political economy model that dominates our legal and political imagination. As such, it aims at examining the conceptual structure of what I call the free market of legal ideas model. Secondly, this paper aims at describing and analyzing an alternative model of political economy that would best explain the real dynamics that regulate the generation, exchange, and use of legal knowledge. To achieve this objective, the paper highlights the conceptual structures that form what I call the colonial model of the production of legal knowledge. Therefore, the paper seeks to specify the subject of legal knowledge production established by these two models, as well as their concepts of time and space. Likewise, it seeks to specify the precise rules and principles that determine the ways in which these models imagine the production, exchange, and use of legal knowledge.
\end{abstract}




\section{Introducción}

La producción, intercambio y uso del conocimiento jurídico están sometidos a una economía política. ${ }^{2}$ Estos procesos no se dan en el vacío, ni se desarrollan de manera aleatoria; están regidos por una serie de reglas y principios que determinan las condiciones de posibilidad para la creación, comercio y consumo de teoría, dogmática y prácticas jurídicas. Estas reglas y principios precisan de quién y dónde se puede crear conocimiento jurídico, cómo se legitima este conocimiento, cuáles son los canales apropiados para su difusión, quién puede usarlo adecuadamente y cómo puede usarse de manera efectiva. La economía política del conocimiento jurídico contribuye con la construcción de nuestra imaginación jurídica y política y, por tanto, condiciona la manera como construimos, percibimos y describimos el saber jurídico. Esta economía política, consecuentemente, no es neutral. Ella construye un sujeto de conocimiento específico (Kahn, 1999, pp. 77-86) que actúa dentro de un espacio (Kahn, 1999, pp. 55-77) y un tiempo (Kahn, 1999, pp. 43-55) particulares. Más precisamente, esta economía política presupone un sujeto, un espacio y un tiempo que determinan la manera como comprendemos los procesos que permiten el surgimiento, tráfico y consumo del saber jurídico.

La economía política del conocimiento legal, sin embargo, no es solamente un conjunto de conceptos, reglas y principios abstractos. Estos determinan la manera como las personas perciben este campo social y, por tanto, los tipos de conducta que consideran apropiados dentro del mismo. ${ }^{3}$ De esta manera, posibilitan y, al mismo tiempo, limitan el accionar de los operadores jurídicos. Las consecuencias prácticas que produce, por consiguiente, no son menores. Cuestiones como cuáles son los contextos de producción de conocimiento jurídico que se considera ricos y pobres, cuál es el valor que se le debe otorgar a las ideas jurídicas que se producen en uno $u$ otro contexto, cuál es la dirección que toma el intercambio de saber jurídico, cuáles son los temas que se consi-

2 Por economía política entiendo la descripción y análisis intelectual de un sistema de producción, distribución e intercambio. En este caso el bien que se produce, distribuye e intercambia es el conocimiento jurídico. (Clark, 1998, pp. 18-20)

3 Sobre la relación entre conceptos y prácticas véase Kahn (2011), p. 93. deran objetos de estudio valiosos, cómo y dónde se deben hacer públicos estos saberes y qué personas o instituciones pueden hacer un uso adecuado de los mismos son condicionadas por la economía política del conocimiento legal que en un momento histórico dado domina nuestra imaginación jurídica y política.

Entender, analizar y evaluar esta economía política, por ende, nos permitirá comprender cuestiones prácticas que afectan nuestras comunidades políticas diariamente. Nos permitirá entender cuestiones como por qué los trasplantes jurídicos típicamente son exportados por países localizados en el Norte Global e importados por el Sur Global; por qué la gramática del constitucionalismo moderno tiene como fuente principal a un pequeño grupo de teóricos políticos europeos y norteamericanos $y$, por qué los productos constitucionales del Sur Global aparecen en las márgenes del mercado global de las ideas jurídicas (BoniIla, 2013a); por qué hoy en día un número muy grande de académicos del derecho del Sur Global pueden reconocer y hablar con algún conocimiento de causa de sentencias como Roe vs. Wade ${ }^{4}$, sin embargo, pocos pueden mencionar la sentencia que despenalizó el aborto en Canadá 5 y muchísimos menos, la sentencia que despenalizó parcialmente el aborto en Colombia. ${ }^{6}$

Examinar la economía política que controla la producción de conocimiento jurídico también nos permitirá comprender por qué los trabajos de autores como Ronald Dworkin, John Rawls, H.L.A. Hart y Richard Posner son ampliamente conocidos en el Sur Global e influencian la manera como las cortes deciden casos polémicos, las formas en que se estructuran los programas de los cursos de teoría jurídica o los campos de investigación que se consideran prestigiosos y útiles. Finalmente, puede ayudarnos a comprender, atendiendo a las consecuencias micro de estos conceptos, reglas y principios, y evidenciando cómo lo personal tiene dimensiones políticas, por qué cuando durante varios años entré a los Estados Unidos los oficiales de inmigración no creían que pudiera ser un profesor visitante en una facultad de

4 Roe v. Wade, 410 U.S. 113, 153 (1973).

5 R. v. Morgentaler, 1 S.C.R. 30 (1988).

6 Corte Constitucional Colombiana, Sentencia C-355/06, M.P. Jaime Araujo Rentería y Clara Inés Vargas Hernández. 
derecho estadounidense, como lo indicaba el formato que debía presentarles cada vez que entraba al país, e insistieran en preguntarme si yo era un pasante en la institución a la que estaba vinculado; o por qué en un seminario sobre educación experiencial en una universidad de elite brasileña los expositores centrales del evento fueron dos profesores estadounidenses con una producción académica menor, que pertenecían a una facultad de derecho débil, mientras en el auditorio y en los paneles había profesores latinoamericanos con una producción académica y una experiencia profesional mucho más rica.

En consecuencia, este escrito tiene un doble objetivo. Por un lado, busca describir y analizar el modelo de economía política que domina la imaginación jurídica contemporánea. En esta medida, busca examinar la estructura conceptual de lo que quisiera llamar el modelo del libre mercado de las ideas jurídicas. Más precisamente, tiene como fin hacer explícitos el tipo de sujeto de producción de conocimiento jurídico al que da lugar el modelo, así como a la manera como imagina el tiempo y el espacio en el que este sujeto se sitúa. De igual forma, busca hacer explícitas las reglas y principios más precisos que determinan la manera como este modelo imagina la producción, intercambio y uso del saber legal, y las razones que explican por qué este modelo ha logrado capturar la imaginación jurídica contemporánea.

Por el otro lado, busca describir y analizar un modelo de economía política alternativo que, desde mi punto de vista, explicaría de mejor manera (pero no justificaría) las dinámicas reales que regulan la generación, tráfico y uso del conocimiento jurídico. Para conseguir este objetivo, hago explícitas las estructuras conceptuales que conforman el que quisiera llamar el modelo colonial de producción de conocimiento jurídico. En consecuencia, presentaré el tipo de sujeto que construye, así como los argumentos con los que nombra y caracteriza el tiempo y el espacio en el que este se localiza. De la misma manera, expondré las reglas y principios que controlan sus procesos de producción, intercambio y uso de conocimiento jurídico. Finalmente, haré explícitas las razones que explican la existencia e impacto práctico del modelo.

El sujeto que crea el modelo del libre mercado de las ideas jurídicas y que expongo en la primera parte de este escrito, es un sujeto abstracto, autónomo y racional que puede concretarse en cualquier individuo de la especie humana. Este sujeto tiene la potencialidad de crear, intercambiar y usar conocimientos jurídicos de la misma manera como tiene la capacidad de articular y transformar proyectos morales y tiene un sentido de la justicia. El espacio en el que este sujeto se mueve es el de una geografía abierta, global, en donde las fronteras estatales son irrelevantes. Es un espacio libre en donde los intercambios fluidos e igualitarios de saber jurídico son la regla y en donde los límites del conocimiento que se crea están dados por el esfuerzo y los talentos individuales.

El tiempo en el que se localiza este sujeto es lineal pero infinito. El conocimiento pasado es la base para la creación del nuevo conocimiento que tiene como objetivo aprehender la verdad o enfrentar los retos básicos de una comunidad política: cómo alcanzar la paz y la prosperidad. No obstante, este es un proceso que no termina nunca en tanto que los continuos cambios en la naturaleza y la sociedad exigen que estemos constantemente adaptando nuestros conocimientos jurídicos y la finitud humana hace que usemos indebida o imprecisamente la razón. Este modelo está guiado por el principio de la meritocracia que explica la creación de ideas jurídicas en un contexto y no en otro como consecuencia de la sumatoria de una serie de decisiones individuales que se entrelazan con la disciplina y el trabajo de quienes las hacen realidad. El triunfo de una idea es consecuencia de su poder explicativo, analítico o normativo. La preeminencia de un argumento en el debate académico tiene que ver, también, con la utilidad que muestra para resolver los problemas jurídicos y políticos de la comunidad. Este modelo ocupa un lugar predominante en nuestra imaginación jurídica dado que se entrecruza, nutre y sirve a valores centrales de la modernidad ilustrada y liberal con la que estamos comprometidos/verdad, objetividad, ciencia, igualdad, autonomía y la convicción de que el derecho es una condición necesaria para la estabilidad política y el bienestar individual y social (Roy, 2008).

El modelo de intercambio de conocimiento jurídico colonial, que expongo en la segunda parte de este artículo, concibe el sujeto, el tiempo y el espacio de 
maneras alternativas. El sujeto de este modelo está territorializado y racializado. Es un sujeto que tiene como elemento definitorio de su identidad el lugar en el que se localiza, típicamente cartografiado como el Sur Global o el Norte Global, la colonia o la metrópoli. El primero es el espacio que ocupan los no blancos; el segundo el de los blancos. Este sujeto, dependiendo de su identidad, además, es historizado, considerado implícitamente como ahistórico o como un componente menor de una tradición jurídica a la que llega tardíamente (Morris \& Spivak, 2010). El sujeto entonces bien puede ser considerado un sujeto de derechos y un sujeto con la capacidad de crear conocimiento jurídico, o un bárbaro jurídico, un objeto de derechos, que solo tiene la capacidad de difundir, reproducir o aplicar localmente el conocimiento creado en otras geografías.

El tiempo de este modelo colonial de producción de conocimiento jurídico es lineal pero finito. El tiempo es una cadena compuesta por una serie de momentos que termina en el derecho de la metrópoli y en sus dinámicas de producción de conocimiento jurídico. La generación, intercambio y uso del saber legal de la colonia está marcado por su interacción con el derecho de la metrópoli. El pasado jurídico de la colonia no existe, es irrelevante para la creación de conocimiento jurídico. El presente es un continuo esfuerzo por avanzar un nuevo eslabón en la cadena; un esfuerzo por alcanzar el estatus que ha logrado el derecho de la metrópoli y por crear el tipo de saber jurídico que esta produce. El futuro, se concibe como un punto final en donde la colonia se identifica con la metrópoli, esto es, el momento que reproduce internamente las condiciones de posibilidad que existen en la metrópoli para la creación de conocimiento jurídico. La metrópoli, por tanto, está situada al final de la historia; la metrópoli está ya en el punto último de desarrollo. Su pasado y su futuro colapsan en un presente eterno y unitario. El tiempo de la metrópoli no está fraccionado; se percibe como uno.

La geografía conceptual del modelo colonial de producción de conocimiento jurídico es binaria. El espacio de este modelo está constituido por el Norte y el Sur Globales. ${ }^{7}$ El espacio constituido por estas ca-

7 Norte Global y Sur Global son ciertamente categorías generales. tegorías es un espacio conceptual, no literal; no son términos que nombren geografías materiales. Estos términos hacen referencia a la distribución desigual del poder de creación e intercambio de conocimientos jurídicos (Mickelson, 2009). Esta distribución desigual, claro, no está aislada sino que se entrecruza con una distribución desigual de poder político, económico, militar y cultural (Mickelson, 2009). El Norte Global nombra un conjunto de países que son políticamente estables, relativamente ricos, militarmente poderosos y culturalmente hegemónicos, en gran medida por su pasado imperial. El Sur Global nombra a un grupo de países, políticamente inestables, relativamente pobres, militarmente débiles, o por lo menos no tan fuertes como los países del Norte Global, y culturalmente subordinados, en parte por su pasado colonial. El espacio del modelo colonial de creación de conocimiento jurídico, por ende, es de una sola vía; es un modelo de intercambio de saberes unidireccional/el Norte Global crea y exporta conocimiento jurídico mientras que el Sur Global importa, difunde, reproduce y aplica localmente este saber.

Las reglas y principios que regulan el modelo están construidos a partir de una serie de oposiciones con-

Nombran una realidad heterogénea compuesta por conjuntos muy disimiles de países. Ni en términos políticos o económicos ni en términos de creación de conocimiento jurídico es lo mismo hablar de Alemania y Estados Unidos o de España y Portugal; como tampoco es lo mismo hablar de China e India o Surinam y Malasia. No obstante, estos términos resultan útiles para nombrar las relaciones desiguales que existen entre los países de Europa Occidental y Norteamérica, por un lado, y los países Latinoamérica, Asía (excluyendo a Japón) y África, por el otro. Estas categorías resultan mas útiles que las ya desgastadas países en vías de desarrollo y países desarrollado o países del primer, el segundo y el tercer mundo. Además, no resultan menos generales que otras categorías que se aceptan pacíficamente como Occidente u Oriente. Las críticas que típicamente se ofrecen en contra del uso de las categorías Norte y Sur Globales cabrían también para otras categorías con un alto grado de generalidad como "Latinoamérica" o "Estados Unidos". Estas categorías se usan no solo para nombrar un hecho geográfico o legal, esto es, la existencia de una subregión del continente americano o un Estado-nación. Estas categorías se usan para dar unidad social, política, cultural y económica a realidades sociales, políticas, culturales y económicas muy distintas. México no es lo mismo que Brasil y Ecuador no es lo mismo que Belice; el Este y el Oeste de los Estados Unidos o el Sur y el Norte de este país son realidades notablemente diferentes. Algunas secciones del Sur estadounidense pueden tener mas similitudes con Latinoamérica que con el Noreste de este país. Sin embargo, usamos diariamente estas categorías y aceptamos pacíficamente sus límites descriptivos. 
ceptuales que describen y evalúan los espacios de nuestra imaginación política y jurídica que ocupan las categorías Sur Global y Norte Global. Las cuatro principales son las siguientes: mímesis/autopoiesis, conocimiento local/conocimiento universal; cultura/ derecho; y lenguas aptas para el conocimiento jurídico/lenguas inútiles para el conocimiento jurídico. Estas oposiciones conceptuales van de la mano con un conjunto de razones que intentan explicar por qué el Norte Global es un contexto rico para la producción de conocimiento jurídico y por qué el Sur Global es un contexto pobre en esta materia. Estos argumentos hacen referencia al formalismo de las comunidades jurídicas del Sur Global ${ }^{8}$, al hecho de que estas son iteraciones menores de las grandes familias jurídicas del mundo, la romano-germánica y la angloamericana, ${ }^{9}$ a las debilidades de las comunidades académicas del derecho del Sur Global (Bonilla, 2013c), la enorme influencia que ha tenido el derecho estadounidense en esta parte del mundo, ${ }^{10}$ a la supuesta autosuficiencia de las comunidades jurídicas del Norte Global (Mattei, 1998) y a la relación imperial directa o indirecta que se ha dado entre países del Norte y el Sur globales.

El artículo, como puede verse, tiene unos objetivos descriptivos, analíticos y críticos. Así, mientras que en la primera parte del escrito expongo y examino el modelo normativo que controla la manera como imaginamos la producción de teoría, dogmática y prácticas jurídicas; en la segunda, presento y estudio el modelo que determina las prácticas reales de producción e intercambio de estos saberes. El objetivo primordial del escrito, por tanto, es comprender las estructuras conceptuales que determinan la manera como interpretamos la generación, intercambio y uso del saber jurídico. Los argumentos críticos aparecerán solo de manera puntual, típicamente a través de los ejemplos que ilustran los argumentos generales. El fin del texto, quisiera enfatizar, no es normativo. No pretende precisar los ideales hacia los cuales deberían dirigirse los operadores jurídicos. La reforma de los conceptos y prácticas que consideramos cuestio-

8 Véase, Kahn (2011).

9 Véase Santos (1995); Hoecke \& Warrington (1998).

10 Véanse Merryman \& Pérez-Perdomo (2007); Kelemen \& Sibbitt (2004); Merryman (1977); Ritttich (2006). nables es un objetivo loable y muy común en la academia jurídica (Kahn, 2011). Sin embargo, cualquier esfuerzo transformador debe basarse en un buen diagnóstico del tema que se estudia. La descripción y el análisis, además, no necesariamente deben ir de la mano de las críticas y las propuestas de cambio. Es deseable que exista una división del trabajo académico que promueva la diversidad de aproximaciones teóricas y metodológicas. La reforma no es el único objetivo que debe perseguir la investigación jurídica.

Ahora bien, no argumento que el modelo del libre mercado de las ideas jurídicas sea solo un modelo normativo sin ninguna implicación práctica o que el modelo de la economía colonial no ocupe ningún espacio en nuestra imaginación jurídica y política. Lo que quiero decir es que tanto uno como otro conviven en nuestra teoría y nuestras prácticas jurídicas en profunda disonancia cognitiva. Los dos ocupan un lugar en la manera como conceptualizamos y producimos, intercambiamos y usamos el saber jurídico. Nuestra imaginación legal no es, por tanto, un todo coherente. Está compuesta por diversos elementos organizados jerárquicamente que responden a justificaciones disímiles que entran continuamente en contradicción.

El primer modelo, el de la economía de mercado, está en el centro, mientras que el segundo, el de la economía colonial, está en la periferia de nuestra imaginación jurídica normativa. El primero, además, funciona inintencionadamente como un manto conceptual que oscurece la presencia del segundo en nuestras prácticas y discursos. La posición medular que ocupa en nuestra imaginación jurídica y política normativa tiende a ocultar las dinámicas del modelo colonial. El modelo del libre mercado de las ideas jurídicas no tiene como objetivo encubrir al modelo colonial. No obstante, en la práctica tiende a cumplir con esta función. Valores como la autonomía individual y la meritocracia, que supuestamente explican la creación, legitimación y uso del conocimiento jurídico, impiden que las relaciones de poder verticales entre la academia jurídica del Norte y el Sur Globales puedan explicitarse y evaluarse.

Los dos modelos, es importante precisar, no son aceptados pacíficamente por toda la academia jurí- 
dica del Norte y el Sur globales. ${ }^{11}$ Ciertamente, hay espacios que podríamos llamar de crítica, resistencia y emancipación epistemológica. Académicos de una y otra región han criticado los modelos y han articulado prácticas alternativas de producción, intercambio y uso de conocimiento jurídico. Agrupaciones de académicos o movimiento intelectuales como Third World Approaches to International Law (TWAIL) (Mutua, 2000) y los estudios postcoloniales del derecho (Ruskola, 2002), por ejemplo, buscan cuestionar de manera directa el modelo colonial de producción de conocimiento jurídico y crear productos jurídicos originales que tengan en cuenta los contextos propios del Sur Global. No obstante, estos espacios de resistencia y emancipación no serán examinados en este escrito. Lo serán en otro texto que hace parte de este mismo proyecto de investigación.

\section{El libre mercado de las ideas jurídicas}

\subsection{El sujeto de conocimiento}

En el centro del modelo de la economía de mercado de las ideas jurídicas se encuentra un sujeto abstracto, autónomo y racional. Este sujeto desencarnado tiene la capacidad de crear, intercambiar y usar conocimiento jurídico. Es un tipo de individuo comprometido con la búsqueda de la verdad y con la solución de los problemas básicos de la comunidad política: la violencia y la creación de las condiciones que permitirán la prosperidad de los asociados. Este sujeto no tiene una identidad particular. Lo que resulta relevante es que como miembro de la especie tiene la capacidad de crear conocimiento jurídico haciendo uso de la razón. No importa su etnia, su género, su raza o su lugar de nacimiento. La capacidad de crear, intercambiar y usar los conocimientos jurídicos es ajena a los accidentes que constituyen su individualidad. Ahora bien, poner en acción esta facultad de manera que efectivamente se cree conocimiento jurídico es consecuencia de la decisión libre de cada sujeto. Los productos que genere, así como su calidad y utilidad, dependerán fundamentalmente de su trabajo, disciplina y compromiso con la verdad y el florecimiento de su comunidad política. El modelo, por tanto, está también comprometido con la igualdad. Todos los sujetos de conocimiento son iguales en su capacidad para crear conocimiento jurídico.

11 Véase, Dominguez \& Baert (2000).
No hay, a priori, mandarines del saber jurídico. El reconocimiento que se le da a los sujetos es consecuencia del valor de verdad y la utilidad de los conocimientos que producen. La comunidad política moderna reconoce formalmente este valor a través de los derechos de propiedad intelectual. El esfuerzo individual debe ser recompensado. No obstante, los créditos que este genera deben ponderarse con la utilidad social del producto generado y con la posibilidad de que todas las personas puedan usarlo. De ahí que los derechos de propiedad intelectual típicamente estén limitados temporalmente.

El sujeto que crea el modelo del mercado de las ideas jurídicas se captura de manera paradigmática en la escultura de Charles Degeorge, la Juventud de Aristóteles. ${ }^{12}$ En el centro de la imagen aparece un joven (Aristóteles) sentado en un sillón leyendo. Sobre sus piernas tiene un libro abierto; en su mano derecha una esfera de metal. Justo debajo de esta hay un platón también de metal. Si el joven se duerme, la bola caerá de su mano y golpeara el recipiente generando un ruido que le despertará. La búsqueda del saber, en nuestro caso, del saber jurídico, es fruto del esfuerzo y el compromiso individual. El joven es la imagen de cualquier ser humano. La verdad y la producción de conocimiento útil para nuestra comunidad política están al alcance de cualquier sujeto. Lo único que se necesita es un acto de voluntad que ponga en acción y sostenga la capacidad que todo ser humano tiene de crear conocimiento jurídico. El joven, uno de los filósofos occidentales paradigmáticos, se sienta en el sillón voluntariamente y planea e implementa una estrategia que le permitirá avanzar en su trabajo intelectual; avanzar en la búsqueda de la verdad. Su compromiso con la ciencia, en nuestro caso con la ciencia del derecho, no tiene límite distinto a sus capacidades intelectuales y de trabajo.

El sujeto de conocimiento de este modelo, además,

12 Charles Degeorge, Jeunesse d'Aristote, 1875. La escultura se encuentra en el Museo de Orsay. En la siguiente página puede verse una fotografía de la escultura: http://www.musee-orsay.fr/fr/collections/catalogue-des oeuvres/notice.html?no_ cache $=1 \& z o o m=1 \& t x \_d a m z o o m \_p i 1[z o o m]=0 \& t x \_d a m z o o m \_$

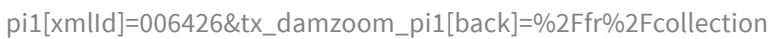
s\%2Fcatalogue-des-oeuvres\%2Fnotice.html\%3Fno_cache $\% 3 D 1 \%$ 26nnumid\%3D006426\%26cHash\%3D66848a1aa7. 
está comprometido con la idea de que el derecho es una condición necesaria para el orden y la prosperidad de la comunidad política. El contractualismo, central para la justificación de las comunidades políticas modernas, lo muestra de manera paradigmática. El modelo del libre mercado de las ideas jurídicas, claro, es solo un componente de un modelo político mucho más amplio y ambicioso: el liberalismo. El paso del estado de naturaleza al estado civil debe darse de manera que la vida, la integridad de las personas y sus bienes puedan garantizarse (Boucher \& Kelly, 1994). En el estado de naturaleza la violencia es la regla (Hobbes, 2013) o está siempre latente a pesar del relativo aislamiento en el que viven los individuos (Locke, 1991). Los derechos naturales que tenemos sobre nuestro cuerpo y nuestros bienes están siempre en peligro de ser violados en este momento pre-político. El problema fundamental que enfrentan los sujetos que se imaginan viviendo en esta situación es que no existe un tercero imparcial que pueda resolver sus conflictos (Locke, 1991, p. 294). De ahí que a través de un acuerdo libre los sujetos decidan crear el Estado y someterse a su poder. Ahora bien, el derecho positivo resulta una herramienta necesaria para garantizar la vida y la propiedad de los asociados (Hobbes, 2013, pp. 233-252). Este precisa el contenido de los derechos naturales y los hace exigibles frente al Estado y a los otros ciudadanos. Sin derecho no habría comunidad política y sin comunidad política no habría vida, integridad personal, estabilidad y prosperidad.

En esta medida el contractualismo identifica el derecho con la polis y la polis con civilización. Fuera de la polis no hay derecho positivo; tras las murallas que protegen a la comunidad política solo hay violencia. El otro del derecho es entonces la violencia (Kahn, 2000; 2008). El otro del ciudadano, que lo es como consecuencia de su autonomía y del derecho, es el bárbaro; aquel que no tiene un Estado que aplique el derecho positivo, claro y preciso, que genera. De ahí que el sujeto de conocimiento que crea el modelo del libre mercado de ideas jurídicas esté ineludiblemente relacionado con su otro, el bárbaro. Aquel que vive en el estado de naturaleza.

\subsection{El tiempo}

El tiempo en el que habita el sujeto es lineal e infinito. El derecho moderno está estructurado alrededor de dos valores, voluntad y razón (Kahn, 2011, pp. 7-30), que el modelo del libre mercado de las ideas jurídicas presupone. Para que el derecho sea válido y legítimo debe ser a la vez fruto de la soberanía popular y de la razón humana. Sin embargo, la voluntad popular cambia continuamente de opinión, las circunstancias naturales y sociales en las que habitan los seres humanos están en constante devenir, y las personas fallan frecuentemente en el uso de la razón. El pasado, por ende, es fundamental para la creación, intercambio y uso del saber jurídico. El nuevo conocimiento se basa en los aciertos y aprende de los errores cometidos en el pasado. El conocimiento jurídico, como cualquier otro conocimiento, es acumulativo. El presente es siempre un intento por satisfacer tanto la voluntad como la razón. Un proceso de ensayo y error que busca al mismo tiempo conseguir la aquiescencia de los asociados y llegar a la verdad. El futuro, por tanto, no tiene final. La creación, intercambio y uso del conocimiento jurídico nunca termina. El futuro se presenta siempre abierto dadas las características de la naturaleza, la finitud humana y los valores morales y políticos con los que estamos comprometidos.

Los congresos de las democracias liberales modernas producen leyes de manera sistemática y continua. Para sus ciudadanos esta es una obviedad que se acepta pacíficamente. Lo que no es comúnmente conocido son los ejes conceptuales que motivan esta dinámica. La voluntad y la razón están constantemente corrigiéndose (Kahn, 2011, pp. 7-30). La razón enmienda los errores de la voluntad, que puede no ser algo distinto a los intereses creados y las pasiones momentáneas o permanentes (Elster, 1998). La voluntad le recuerda constantemente a la razón que sin el concierto de los asociados, que se manifiesta usualmente a través de sus representantes, solo tendríamos un conjunto de normas inválidas e ilegítimas (Kahn, 2011). Tanto una como otra, la razón y la voluntad, están atentas a los cambios sociales, las transformaciones en el entorno natural, y las fallas humanas, de manera que el derecho pueda responder adecuadamente a las necesidades o retos que todas estas circunstancias generan.

Si la razón pudiera llevarnos a la verdad jurídica y los legisladores pudieran hacer un uso adecuado de esta herramienta, el congreso solo debería legislar 
una vez sobre cada tema. El soberano solo tendría que aceptar las conclusiones a las que la razón ineludiblemente lo lleva y votar a favor de los proyectos de ley que las articula en un lenguaje jurídico claro y preciso. Este era el ideal detrás del Código Civil de Napoleón (Mirow, 2001; 2005). El legislador aceptaría las creaciones de un conjunto de expertos que haciendo uso de la razón crearían un conjunto de normas jurídicas que regularían todo el campo de estudio (las relaciones entre particulares) de manera permanente (Bonnecase, 1944). Las normas jurídicas creadas tenían vocación de eternidad. De ahí también que estas normas pudieran serle impuestas a los pueblos que eran conquistados en las campañas napoleónicas. ${ }^{13}$ Napoleón, no hay que olvidarlo, adelantaba sus campañas militares llevando en una mano la espada y en la otra el código civil. El derecho, fruto de la razón, era inmune a las diferencias culturales y al hecho de que este era percibido como heterónomo por parte de las comunidades derrotadas militarmente. ${ }^{14}$

Si la voluntad del soberano es el único elemento que guía la creación de normas jurídicas, estaríamos ante el imperio del capricho, la intuición, los intereses creados y las pasiones momentáneas y permanentes (Elster, 1988). Las normas jurídicas probablemente estarían basadas en argumentos empíricos errados o serían cuestionables moral o políticamente. La voluntad, por más que sea la voluntad del soberano, debe ser siempre guiada, limitada, por la razón. De ahí que el realismo jurídico estadounidense, por ejemplo, estuviera comprometido con la idea de que las ciencias sociales deberían guiar tanto las creaciones de normas jurídicas en el legislativo como en la judicatura (Llewellyn, 1949). La economía y la sociología, entre otras, contribuirían con argumentos racionales sólidos a la creación de leyes y sentencias.

13 Napoleón señaló a este respecto: "Mi verdadera Gloria no es que haya ganado cuarenta batallas. Waterloo hará que el recuerdo de estas victorias desaparezca. Lo que nada puede hacer desaparecer y vivirá eternamente es mi Código Civil" (Bergel, 1988, pp. 1078-1079).

14 “[E]l Código Civil Francés de 1804 fue visto como un tipo de libro popular que podía ser puesto en el anaquel junto a la Biblia de la familia, o, tal vez, en vez de esta. Sería un manual para el ciudadano, claramente organizado y presentado en un lenguaje directo que permitiría que el ciudadano determinara sus derechos y obligaciones jurídicas por sí mismos." (Merryman \& Pérez-Perdomo, 2007, p. 29).
Estos procesos de creación jurídica no deberían estar guiados por la intuición, la buena fe, o los compromisos valorativos de legisladores y jueces. De ahí también el énfasis que hace el análisis económico del derecho en que legisladores y jueces basen sus decisiones en un análisis costo - beneficio que prioricen el valor de la eficiencia y estén guiados por modelos matemáticos (Posner, 1973). La ciencia, en este caso, las ciencias sociales deberían guiar la voluntad del pueblo que se manifiesta a través del legislador o del juez que interpreta sus mandatos.

\subsection{El espacio}

El espacio que concibe el modelo, que se cruza con las coordenadas temporales descritas y dentro del cual actúa el sujeto que construye, es el del globo teráqueo. Este espacio se imagina como una geografía abierta que considera a las fronteras nacionales como fundamentalmente irrelevantes. El único límite espacial que tiene el sujeto de conocimiento es el de las orillas materiales de nuestro planeta. El saber jurídico puede crearse, intercambiarse y usarse desde cualquier parte del globo. El flujo y uso de este conocimiento es multidireccional y descentralizado. El conocimiento jurídico tiene la potencialidad de surgir en cualquier parte del mundo y no tiene unos canales o patrones de difusión predeterminados. La importación y exportación de conocimiento jurídico puede darse desde cualquier punto y hacia cualquier punto. Cuáles son los temas que se investigan, cuáles son las ideas que terminan dominando la imaginación de las personas, cuáles son los medios y el lenguaje que vehiculan el conocimiento creado, entre otras cosas, es fruto de un conjunto inmenso de pequeñas decisiones tomadas por los miembros de la comunidad creadora de conocimiento; son también consecuencia del poder que tienen los productos jurídicos creados para acercarse a la verdad o resolver los problemas que enfrentan las comunidades políticas.

Estos intercambios con trayectorias múltiples y que no se guían por un poder centralizado, en principio, se dan entre sujetos de conocimiento iguales. El modelo está firmemente comprometido con el principio de igualdad. Los sujetos de conocimiento, en los fundamental, son iguales; tienen las mismas capacidades para crear, intercambiar y usar saber jurídico. Los productos jurídicos generados, ciertamente, pueden 
tener un valor monetario. Lo que puede crear diferencias en cuanto a las capacidades reales que tienen los sujetos para el intercambio y uso del saber jurídico. Sin embargo, esto no siempre es el caso (el conocimiento puede ofrecerse gratuitamente) y cuando se da, su precio está definido por el mercado, esto es, por la relación entre la demanda y la oferta del producto de conocimiento. En esta medida es justo en tanto que está determinado por una infinidad de decisiones autónomas que toman tanto quienes producen conocimiento jurídico como quienes lo requieren.

La productividad y capacidad de intercambio y uso de los sujetos de conocimiento jurídico, en la práctica, está determinada por un conjunto de condiciones institucionales. La producción de conocimiento no se da en el vacío. El sujeto de conocimiento puede estar situado en cualquier parte del mundo pero siempre está localizado. Cuando el sujeto que concibe el modelo actúa en el mundo real se ve afectado por una serie de circunstancias materiales. La existencia de bibliotecas sólidas, financiación pública para la investigación, universidades fuertes y abiertas a todas las personas, y plazas de tiempo completo para los profesores, entre otras cosas, afectan la calidad y sistematicidad de los productos jurídicos que se generan. Salvo el caso excepcional de los grandes creadores solitarios, la existencia y solidez de este tipo de instituciones condiciona a los sujetos de conocimiento. Sin embargo, las fortalezas institucionales de uno u otro contexto de producción están directamente relacionadas con una serie de decisiones tomadas por un conjunto de individuos. Es decir, para el modelo del libre mercado de las ideas jurídicas, son fruto de la autonomía individual y de la creatividad, disciplina y trabajo de los miembros de la comunidad política a la que pertenecen tales sujetos de conocimiento. En la práctica, entonces, se pueden generar desigualdades entre los sujetos de conocimiento particulares, sus instituciones y las comunidades políticas en las que están inmersos. Sin embargo, estas son desigualdades legítimas en tanto que son consecuencia de la autonomía de la voluntad de los miembros de una u otra comunidad científica y política.

\subsection{Las reglas y principios}

El modelo del mercado libre de las ideas jurídicas tiene como principios centrales los de la verdad, la utilidad y la meritocracia. Las mejores ideas jurídicas son las que triunfan; son las que logran apropiarse de nuestra imaginación jurídica y política. Los criterios para determinar cuáles son estas ideas son el de la verdad y la utilidad. Las ideas más poderosas son aquellas que se entienden como verdaderas, cualquiera que sea el conjunto de criterios de primer nivel que determinen qué es lo verdadero, y la potencialidad que tienen para describir, analizar, evaluar y, principalmente, solucionar, los retos que enfrentan las comunidades políticas. Las personas que generan este tipo de productos y logran el reconocimiento de sus pares y sus comunidades, son quienes tienen la disciplina, compromiso, creatividad y dedicación para generar productos jurídicos con altos niveles de calidad.

Ciertamente los talentos innatos que tienen algunos sujetos son una variable ajena a la autonomía de las personas. El azar les otorgó algunas ventajas para crear conocimiento jurídico. Así, pueden tener, por ejemplo, mentes con capacidades analíticas y de abstracción superiores a las del promedio de personas, pueden tener una imaginación analógica poderosa o una facultad para la libre asociación que les permite hacer conexiones innovadoras entre realidades conocidas y aceptadas. Sin embargo, los talentos naturales no actúan por si solos. Necesitan de la voluntad de quienes los poseen para ponerse en acción. Los sujetos de conocimiento talentosos pero perezosos usualmente no llegan muy lejos.

La expansión del modelo penal adversarial en Latinoamérica (Domingo \& Sieder, 2001; Torres, 2007), la flexibilización de los mercados laborales en esta misma región de América (Murillo, 2005, pp. 441-443), la omnipresencia del modelo liberal positivista para describir y justificar el derecho (Leiter, 2013), la prioridad que en muchas partes del mundo se le da a los derechos individuales por sobre los derechos sociales económicos y culturales (Donnelly, 2003, cap. 2), la importación de la teoría y práctica pro bono alrededor del mundo (Steinitz, 2009, p. 205) y la inclusión de la educación jurídica clínica en los programas de las facultades de derecho a lo largo y ancho del globo (Wilson, 2004, p. 427), por ejemplo, se explican por el modelo del mercado libre de las ideas jurídicas apelando a la idea de meritocracia que presupone los conceptos de sujeto, tiempo y espacio antes des- 
critos. Estas teorías, dogmática y practicas jurídicas se han regionalizado o globalizado porque describen de mejor manera la realidad, están mejor justificadas que las perspectivas rivales y permiten enfrentar de mejor manera los retos comunes de las comunidades políticas contemporáneas, por ejemplo, como juzgar penalmente de manera justa y efectiva a las personas; cuáles son los criterios para determinar la validez y la legitimidad de las normas jurídicas; cómo incrementar la productividad y los niveles de empleo; cómo potenciar la autonomía individual y permitir que los representantes de los ciudadanos tomen decisiones sobre dónde deben invertirse los recursos económicos de la comunidad; cómo enfrentar los problemas de acceso a la justicia; y cómo educar abogados que sean socialmente responsables y tengan las destrezas para desempeñarse eficientemente en la práctica profesional.

El caso del trabajo jurídico pro bono puede ayudar a ilustrar de manera más detallada el modelo. ${ }^{15}$ Los abogados latinoamericanos han realizado trabajo jurídico gratuito para personas de bajos recursos o el interés público desde hace décadas, sino siglos. Sin embargo, este trabajo era informal en sus procedimientos e individual en su materialización, esto es, dependía de la buena voluntad de cada abogado para su ejecución. En contraste, durante los últimos 15 años los abogados de las grandes firmas de abogados latinoamericanas han promovido la institucionalización del trabajo pro bono dentro de sus organizaciones (The Association of the Bar of the City of NY, 2002). Este proceso se vio impulsado por la importación/exportación de las prácticas y teorías descriptivas y normativas articuladas por las grandes firmas de abogados de los Estados Unidos, principalmente las de Nueva York, y la academia jurídica estadounidense. ${ }^{16}$

15 Sobre el trabajo pro bono en general véase Cummings \& Rhode (2010); y White (2000).

16 “El Centro Cyrus R. Vance para las Iniciativas de Justicia Internacional del Colegio de Abogados de la Ciudad de Nueva York, ha venido colaborando, como parte de sus programas, con abogados, colegios de abogados y organizaciones no gubernamentales en Sudamérica apoyando esfuerzos locales para promover e institucionalizar los servicios jurídicos pro bono (...) S. Todd Crider, socio de Simpson Thacher \& Bartlett, quien dirige el comité del colegio en el Centro Vance, afirma que en Sudamérica, hasta hace poco, "el trabajo pro bono no era parte del vocabulario jurídico. Ahora la mayoría de las firmas que tienen un tamaño significativo en estos tres países ha desarrollado una política pro bono, o está en pro-
El modelo del libre mercado de las ideas jurídicas explicaría este trasplante legal apelando a sus conceptos de sujeto, tiempo y espacio. Los argumentos que justifican el trabajo jurídico pro bono en los Estados Unidos y las prácticas que las ponen en acción de manera institucionalizada son la consecuencia de un grupo más o menos amplio de abogados emprendedores, disciplinados y creativos que buscaban enfrentar los problemas de acceso a la justicia de los más pobres en su comunidad política. Tanto las razones justificativas como las prácticas pro bono institucionalizadas surgen en el contexto de las grandes empresas jurídicas de ciudades como Nueva York y Washington (Cummings \& Rhode, 2010, p. 2364). Estas instituciones sólidas y poderosas, que crean las condiciones de posibilidad del trabajo pro bono formalizado (Cummings, 2004), son fruto del esfuerzo y la creatividad de estos mismos abogados. El discurso académico sobre el trabajo pro bono en los Estados Unidos, se agrega, surge de un grupo de profesores de derecho disciplinados y trabajadores que encuentran como un objeto de estudio valioso el de las responsabilidades sociales de los abogados. En esta medida articulan un discurso descriptivo, analítico y normativo sobre las prácticas y argumentos justificativos de sus colegas practicantes. El discurso y práctica del trabajo pro bono, por consiguiente, es fruto del ejercicio de la autonomía de la voluntad de un conjunto de sujetos que ponen en acción su capacidad para crear conocimiento jurídico. La razón es su instrumento; la verdad y la utilidad, sus principios rectores.

La importación/exportación de las prácticas y discursos jurídicos estadounidenses sobre el trabajo pro bono, indica el modelo, son consecuencia de la fortaleza de los argumentos que la justifican y de la utilidad para enfrentar un problema común como es

ceso de hacerlo" (Dean, 2004). Los documentos producidos por el Vance Center sobre trabajo pro bono han sido muy influyentes en Latinoamérica. Tal vez el más importante ha sido la Guía para la Implementación de Programas Pro Bono en las Firmas de Abogados de Latinoamérica ("Guía"). Al respecto dice el Vance Center: "En colaboración con Skadden, Arps, el Vance Center produjo un manual completo que los estudios pueden utilizar en el establecimiento de sus programas pro bono. Este documento, disponible en nuestro sitio web, fue recibido con entusiasmo en toda la región.” Véase http://www2.nycbar.org/vancecenter/images/stories/ pdfs/111811SpanishVersion.pdf; La guía puede leerse en http:// www.probono.cl/wp-content/uploads/2013/08/guia-pro-bono-para-estudios-juridicos-de-latinoamerica.pdf. 
el de la falta de acceso a la justicia por parte de las capas socioeconómicas bajas de la población. Históricamente, Latinoamérica ha articulado y puesto en práctica estrategias para enfrentar sus problemas de acceso a la justicia, por ejemplo, la defensoría pública y la defensoría de oficio (Cappelleti \& Garth, 1996). No obstante, no había articulado estrategias institucionales fuertes en el sector privado para elevar los niveles de protección del derecho individual al acceso a la justicia. El saber jurídico que se crea en torno al trabajo pro bono surge en Estados Unidos por las condiciones del mercado jurídico que permitió la creación de oficinas de abogados compuestas por cientos si no miles de abogados. Surge también, por los problemas de desigualdad que ha enfrentado Estados Unidos que no permiten que sus ciudadanos pobres satisfagan sus necesidades jurídicas y por la existencia de abogados moralmente responsables y bien formados académicamente que conectaron una y otra situación.

Sin embargo, este conocimiento jurídico pudo haber surgido en cualquier parte del globo en donde se dieran las mismas condiciones institucionales. El flujo del saber jurídico en este caso tiene como fuente los Estados Unidos y se mueve hacia el Sur (Latinoamérica), pero bien hubiera podido darse en otras direcciones. Los Estados Unidos bien podrían ser receptores de un saber jurídico análogo. Los canales de intercambio de saber jurídico son multidireccionales y los emisores y receptores de conocimiento jurídico son autónomos e iguales. Los abogados latinoamericanos y estadounidenses, en tanto receptores y emisores de conocimiento jurídico, son pares que mantienen una relación horizontal.

Ahora bien, la interacción entre razón y voluntad tiene unas características particulares en este caso. La razón, el saber jurídico pro bono, busca solucionar un problema creado parcialmente por el derecho de los Estados receptores de este conocimiento: las instituciones y estrategias jurídicas que han adoptado no han sido suficientes para enfrentar el déficit del derecho al acceso a la justicia de sus poblaciones. Sin embargo, la solución no busca un cambio normativo sino un cambio en el sector privado, el del mercado jurídico, dentro de los marcos legales existentes. El esfuerzo, en este caso, no es por crear una nueva nor- ma jurídica sino por generar un cambio en las prácticas de los abogados asesores y litigantes que actúan dentro de las normas de ética profesional establecidas por sus comunidades políticas, directamente por el soberano o con su autorización.

El caso de la importación/exportación de la educación jurídica clínica a Latinoamérica resulta útil para continuar con el ejercicio de hacer explícito el poder explicativo y analítico del modelo del libre mercado de las ideas jurídicas. Durante la década de los 60 y 70 varios países latinoamericanos como Colombia, Chile, y Perú, enfrentaban problemas relacionados con la eficacia y futuro de su modelo de desarrollo (Trubek \& Galanter, 1974, p. 1006). Los niveles de crecimiento económico, desigualdad y empleo no eran los deseables. El diagnostico al que llegaron estos gobiernos latinoamericanos, en diálogo con el gobierno de Estados Unidos, fue que una de las razones que limitaban el desarrollo económico de los países de la región estaba directamente relacionado con el formalismo que caracterizaba a sus ordenamientos jurídicos. Desde el punto de vista teórico estos se describían como sistemas cerrados, completos, coherentes y unívocos. ${ }^{17}$ Esta descripción, se argumentaba, nada tenía que ver con la realidad del derecho en la región: sistemas que, como cualquier otro, interactuaban constantemente con otros conjuntos normativos como la moral y se caracterizaban por ser incompletos, contradictorios y polisémicos. El concepto formalista del derecho, además, daba lugar a un tipo de educación enciclopédica, memorística, descontextualizada, acrítica y legocéntrica. ${ }^{18}$ Esta educación, además, formaba estudiantes con pocas destrezas para la práctica profesional ${ }^{19}$ y sin mayor conciencia sobre sus responsabilidades sociales. Desde el punto de vista práctico, los ordenamientos jurídicos de la región eran vistos como sistemas ritualistas en exceso, lentos y poco atentos a las necesidades reales de los ciudadanos. ${ }^{20}$

\footnotetext{
17 Sobre el formalismo jurídico lationoamericano véase Pérez-Perdomo (2005).

18 Véanse, por ejemplo, los siguientes artículos: Vargas (2008); Macchiavello (2008); Duce (2008); Spector (2008); Mendes (2008); Rodriguez \& Falcão (2008).

19 Véase, e.g., Hernández (2003).

20 "Durante el periodo que estamos examinando en algunas universidades existe la percepción de que las facultades de derecho no le han seguido el paso a los cambios sociales y que los programas de derecho se han quedado atrás. Esta percepción puede ha-
} 
Esta descripción de los sistemas jurídicos latinoamericanos permitía concluir que si se querían aumentar los niveles de desarrollo de los países de la región era necesario cambiar su derecho y las formas de enseñanza jurídica (Gardner, 1980, p. 43). La premisa de la cual partía esta conclusión es que un derecho liberal eficiente era una condición necesaria para el desarrollo (Trubek, 2006, pp. 74-77). Para alcanzar este objetivo, había que atacar el origen del problema: las facultades de derecho. En esta medida los políticos, técnicos y académicos estadounidenses ofrecieron, entre otras cosas, el método socrático y las clínicas jurídicas (Maisel, 2008). Estados Unidos había enfrentado retos análogos y había articulado las soluciones que ahora ofrecía como un producto de exportación. ${ }^{21}$ Décadas atrás había enfrentado problemas relacionados con el formalismo en la teoría, práctica profesional y educación jurídicas (Hoeflich, 1986). Los políticos, técnicos y académicos latinoamericanos concluyeron que estas herramientas estaban sólidamente concebidas y justificadas. También concluyeron que en tanto que habían funcionado en Estados Unidos, bien podrían funcionar en la región. De ahí que países como Colombia expidieran leyes haciendo obligatorios los consultorios jurídicos para todos los estudiantes de derecho. ${ }^{22}$ Estas normas jurídicas, cuarenta y tres años después de que fueran expedidas, todavía siguen vigentes. ${ }^{23}$

ber sido consecuencia de la rapidez con la que se dan los cambios sociales que se opone a los más lentos y difíciles en el currículo y en los métodos de enseñanza en las facultades de derecho. Las sociedades latinoamericanas han venido enfrentando severos problemas de pobreza, marginalidad, criminalidad y brutalidad policiaca, al mismo tiempo que experimentan transformaciones políticas, algunas muy rápidas, una revolución en las comunicaciones y una mayor integración en la economía global. Sin embargo, estos problemas no parecen afectar a las facultades de derecho que aparecen protegidas por una cultura de códigos y libros viejos". Es importante anotar que Pérez-Perdomo también señala cambios en estas materias (Pérez-Perdomo, 2011, p. 63).

$21 \mathrm{El}$ formalismo fue duramente atacado y debilitado por el realism jurídico. Véanse, por ejemplo, Dewey (1924); Llewellyn (1931); Leiter (2010).

22 Véase, e.g., Laing (1974). En el texto se explica la influencia de la tradición jurídica formalista en la educación jurídica colombiana y la revolución que causa la educación experiencial.

23 Los consultorios jurídicos colombianos fueron creados por el Decreto $\mathrm{N}^{\circ} 196$ de 1971 y reglamentados posteriormente por el Decreto № 765 de 1977, la Ley Nº 23 de 1991 y la Ley N 583 de 2000 (Colombia). Véase Toro, B. L. (2003). Las clínicas jurídicas de interés público en Colombia. Retos y posibilidades de una naciente experiencia. In Clínicas de Interés Público y Enseñanza del Derecho (pp. 9-47).
El modelo del libre mercado de las ideas jurídicas describiría y explicaría este proceso de creación, intercambio y uso de conocimiento de la siguiente manera. Por un lado, tenemos un conjunto de sujetos (políticos, académicos y técnicos) situados en un punto del globo que han creado una serie de conocimientos jurídicos que buscan enfrentar un problema jurídico y político particular (la relación inversamente proporcional entre derecho formalista y desarrollo). Estos sujetos ofrecen este producto a un conjunto de sujetos (políticos, académicos y técnicos) situados en otro punto del globo que enfrentan un problema análogo. Las virtudes de este saber jurídico para enfrentar estos retos es consecuencia de las fortalezas (trabajo, disciplina, creatividad) de los individuos que las crearon y de las instituciones académicas y estatales en las que están inmersos. Los sujetos receptores de este conocimiento jurídico encuentran que este es el mejor producto que ofrece el mercado de las ideas jurídicas en ese momento y deciden importarlo. Tanto los emisores como los receptores de este conocimiento son, por tanto, iguales y sus intercambios fluidos.

Por otro lado, los puntos del globo donde están localizados unos y otros son poco relevantes. En este caso el flujo del conocimiento jurídico tuvo una dirección Norte-Sur. No obstante, no es necesario que así haya sido. En este y otros temas presentes y futuros la dirección del flujo bien puede ser Sur-Norte o, por sugerir otra orientación, Oriente-Occidente. El lugar de creación de la teoría o la práctica jurídica es irrelevante. Lo que importa es su valor de verdad y su utilidad. Lo significativo es que es el mejor producto disponible en el mercado de las ideas jurídicas. El mercado de las ideas jurídicas es un espacio abierto que tiene como único límite espacial las fronteras de nuestro globo terráqueo.

Finalmente, tanto en el punto de emisión como en el punto de recepción de conocimiento jurídico se evidencia la interacción entre voluntad y razón que es motor de las continuas transformaciones que experimenta el derecho moderno. El enfrentamiento entre las visiones dominantes del derecho que se presentan como expresión del soberano y la razón y las visiones críticas que se presentan como la voz de la razón, adecuadamente entendida y usada. En Esta- 
dos Unidos tenemos el encuentro entre el liberalismo clásico de la era Lochner y el liberal intervencionista del New Deal (Balkin, 2011). Análogamente, tenemos el enfrentamiento entre la visión clásica de la academia jurídica (Holmes, 1897) representada paradigmáticamente por el decano Langdell y las perspectivas alternativas de la enseñanza del derecho ofrecidas por el realismo jurídico (Frank, 1933). Visiones todas estas que se articulan e implementan jurídicamente o en normas, como las del ABA que tienen un carácter obligatorio para sus miembros. En Latinoamérica, tenemos una interpretación conservadora del liberalismo político que no ve relación estrecha entre derecho liberal eficiente y desarrollo económico y una nueva visión que ofrece el movimiento de derecho y sociedad donde aquel es precondición necesaria para este. Correlativamente, encontramos el choque entre una visión de la academia jurídica que combina el historicismo alemán con la escuela de la exégesis francesa (Medina, 2004) con la interpretación que ofrece el movimiento derecho y desarrollo del realismo jurídico estadounidense (Trubek \& Santos, 2006, pp. 1-3).

El lugar preeminente que ocupa el modelo del libre mercado de las ideas jurídicas dentro de nuestra imaginación legal no es casual. Este es una pieza más dentro del horizonte de perspectivas en el que estamos inmersos. Este horizonte está compuesto en una parte importante por las ideas centrales de la modernidad liberal. Esta tiene como constitutivos conceptos como el de autonomía individual, igualdad, ciencia, objetividad, progreso, verdad, mérito y mercado (Dupré, 2004). El modelo del libre juego de la oferta y la demanda del saber legal es una aplicación y adaptación al campo jurídico de ideas centrales con las que ya muchos ciudadanos de las democracias liberales contemporáneas están comprometidos. La autonomía, racionalidad e igualdad que para el liberalismo caracteriza a los seres humanos y que se traslada luego a los ciudadanos (Rawls, 1996), se mueve ahora hacia el sujeto de conocimiento jurídico.

El saber legal es visto como un producto que no escapa a las leyes de la oferta y la demanda: los productos que se generan, el lugar en donde se crean, su valor y los flujos de difusión e intercambio de estos productos son una consecuencia de la sumatoria de una serie de decisiones tomadas por una multiplicidad de individuos anónimos a lo largo y ancho del globo. El conocimiento, por ende, es considerado y aceptado como una mercancía. Los productos jurídicos tienen un valor económico que determina parcialmente su circulación en el mercado de las ideas jurídicas. La economía política del saber jurídico está comprometida también con la idea de progreso que se puede alcanzar a través de la ciencia, en este caso, de la ciencia jurídica. Un saber que es expresión y desarrollo de la razón que en un proceso de ensayo y error va abriendo el camino que nos llevará a la verdad jurídica y nos mostrará las formas a través de las cuáles este puede ser socialmente útil.

\section{El modelo colonial de producción, intercambio y uso de conocimiento jurídico}

3.1 El sujeto de conocimiento

El sujeto que construye el modelo colonial es dual pero interdependiente. De un lado de la moneda tenemos al sujeto de conocimiento jurídico de la metrópoli; del otro, al sujeto de conocimiento de la colonia. Uno y otro se definen tanto positiva como negativamente; se construyen a partir de lo que son y de lo que no son. El primero es un sujeto que se entiende con la capacidad de crear, intercambiar y usar el saber jurídico. El segundo se concibe como un sujeto que solo tiene la capacidad de reproducir, aplicar localmente y difundir el conocimiento jurídico creado en la metrópoli. El sujeto-metrópoli define su identidad a partir de lo que no es: un bárbaro jurídico. El sujeto colonial a partir de su antónimo, el homo ius. El sujeto-metrópoli se entiende como un sujeto político, es decir, ha logrado salir del estado de naturaleza; tiene un Estado, tiene derecho. El sujeto colonial está todavía situado en el estado de naturaleza. No ha logrado construir una polis que lo eleve por encima de la violencia que pone en continuo peligro su vida y sus bienes. Lo que llama derecho solo lo es en apariencia.

Estos sujetos de conocimiento están, por tanto, territorializados, racializados y tienen una relación particular con la historia. La identidad del sujetometrópoli y del sujeto colonial se define en parte por el lugar donde están localizados, la metrópoli o la colonia, el Norte Global o el Sur Global. El prime- 
ro se entiende como un contexto rico de producción de conocimiento jurídico mientras que el segundo se comprende como un contexto pobre de conocimiento jurídico. La comunidad y tradición jurídica en la que están inmersos determinan la manera como se construye su identidad. El proceso de construcción de la identidad de estos sujetos es, consiguientemente, dialógico. Se crean a partir de la interacción con quien conciben su otro y con su comunidad política y jurídica. Uno no puede existir sin el otro.

El sujeto-metrópoli y el sujeto colonial tienen un color de piel. El territorio que habitan y los define está conceptual, no materialmente, racializado. En la metrópoli el sujeto de conocimiento es blanco; en la colonia, no blanco. La construcción de tradiciones jurídicas ricas o pobres está relacionada parcialmente con la cantidad de melanina que los sujetos tienen en su cuerpo. En el Sur colonial habita el oscuro de piel; en el Norte imperial el claro de tez. El sujeto-imperial se ha identificado en el discurso como caucásico; el sujeto colonizado como negro, marrón, rojo o amarillo. El primero, además, es un sujeto ahistórico jurídicamente. Antes de su contacto con la metrópoli no tenía derecho. No estaba inmerso en una tradición jurídica sobre la cual pudiera pararse y que fuera su base para la construcción de nuevo conocimiento, de conocimiento verdaderamente original. Su historia jurídica empieza cuando es conquistado y colonizado. Su contacto con el derecho de la metrópoli le permite entrar en la historia del derecho. Sin embargo, entra en esta historia no como un hacedor sino como un reproductor o un actor menor de la misma. El derecho de la metrópoli reemplaza al derecho nativo o lo tolera mientras no contradiga sus presupuestos. ${ }^{24}$ El momento pre-histórico, por tanto, se pierde en el tiempo; se vuelve inaudible e inasible. No es un objeto de estudio valioso; no se narra, no se escribe sobre él. El sujeto-colonial no tiene acceso a su pasado jurídico. El segundo, el sujeto-metrópoli, por el contrario, es un sujeto con historia y un sujeto historizado. Está insertado en una cadena intergeneracional que lo conecta con su pasado, que explica su presente y

24 Las Leyes de Indias del imperio español, por ejemplo, reconocían el derecho indígena mientras este no violara las normas imperiales. Véase Recopilación general de las Leyes de Indias, Libro Segundo, Título Primero, Ley iiij. que lo lanza hacia múltiples posibles futuros jurídicos. Su pasado y su presente jurídicos son objetos de conocimiento estimables. Merecen ser conocidos, narrados, fijados en lenguaje escrito. Las identidades de estos sujetos de conocimiento jurídico, entonces, se crean a partir de la manera como se narra su derecho y tradiciones jurídicas (o su ausencia).

Estos sujetos son presentados paradigmáticamente en la novela Esperando a los bárbaros de J. M. Coetzee (2003). El protagonista es un magistrado de una metrópoli que ejerce sus funciones en la colonia, en un desierto, rodeado por bárbaros de color. El imperio no tiene nombre; la colonia y el magistrado tampoco. Son la expresión de la idea misma de imperio y de colonia. Él es el guardián de la civilización; el que trae el derecho a esta tierra de nadie. Es un territorio en donde la violencia y el amor, los otros del derecho, reinan. Los bárbaros se roban, se hieren, se asesinan; los bárbaros son carne y se aman. A través del derecho, el juez busca solucionar los conflictos que surgen entre los bárbaros y que no crean más que inestabilidad y pobreza. El juez también protege a los suyos de este estado de naturaleza. El pueblo/fuerte que regenta es una extensión de la polis que representa. Sus paredes de madera y barro separan materialmente la civilización de la barbarie. No obstante, conceptualmente, estas paredes están constituidas por el derecho. La ley es la que separa a unos de otros.

El poder simbólico y material que concentra, además, está al servicio de los ciudadanos de la metrópoli, particularmente de sus funcionarios. Ellos representan otras facetas de la civilización, traen la civilización a la colonia. Cuando la metrópoli tiene noticias de que los nativos quieren emanciparse sus funcionarios actúan inmediatamente para que la paz retorne a la colonia. El coronel Joll que interroga a un grupo de nativos buscando información sobre los rebeldes, a pesar de sus métodos crueles (la tortura), no quiere otra cosa que traer orden y estabilidad a estas tierras de nadie. Estas son las precondiciones para que él pueda ejercer sus funciones de tercero imparcial entre los salvajes y para proteger a los otros representantes de la metrópoli. Los comerciantes, los recolectores de impuestos, los artistas también juegan un papel en este proceso civilizatorio y deben ser protegidos. 
El magistrado se define a sí mismo a partir de lo que es pero también de lo que no es. Él es la ley y, consecuentemente, él es la civilización. Él encarna una tradición jurídica que ahora busca aplicar en los territorios. Sin embargo, él se define también en contraste con su otro, los nativos con los que interactúa diariamente y a quienes regenta y resuelve los conflictos. Él no es ellos; ellos no son él. Su amante nativa ocasional y la joven a la que recoge luego de que fuera torturada por el coronel se lo recuerdan constantemente. Ellas representan el amor y el deseo. El cuerpo encarnado que tiene sus propias normas, distintas a las normas jurídicas. El oficial, por el contrario, a pesar de su crueldad, comparte una parte de su identidad. Su pertenencia a la metrópoli los hace parte de la misma comunidad imaginada. Cuando el magistrado decide devolver a la joven torturada a su pueblo es luego acusado, apresado y condenado por la metrópoli. El coronel Joll lo acusa de "concertar con el enemigo". Las leyes de la metrópoli, el derecho, se enfrentan a las normas del amor, en este caso una combinación de amor romántico y amor por el prójimo.

Estos sujetos duales pero interdependientes también se recogen de manera poderosa en los cuadros orientalistas del siglo XIX. Estos artistas estaban a la vez fascinados y turbados por los bárbaros (Lemaire, 2001). Eran el otro de la Europa decimonónica. Los pintores orientalistas son grandes maestros del arte europeo de la época que recogen y sintetizan una mirada particular sobre el otro de Europa; no autores menores con miradas idiosincrásicas que nadie distinto a ellos comparte. En las obras Delacroix, Chassériau, Regault, Guillaumet, Tournemine y Barrias ${ }^{25}$ el sujeto colonial se identifica con lo otro del derecho: la violencia y el amor.

El otro, siempre oscuro, es un guerrero sanguinario, habita naturalezas extremas como el desierto o la selva, es cuerpo, en particular, cuerpo femenino erotizado y es amigo o esposo que defiende a sus amados (Rosenthal, 1982). Los temas recurrentes de estos pintores son las escenas de guerra, caza, ani-

25 Algunas de las más reconocidas pinturas orientalistas de estos artistas se encuentran en el Museo de Orsay en París, http://www. musee-orsay.fr/fileadmin/mediatheque/integration_MO/PDF/ Orientalism.pdf Las imágenes que aparecen en este artículo son de obras que se exhiben en este museo. males salvajes y harems o cuerpos femeninos desnudos situados en espacios suntuosos (Stevens, 1984). Los sujetos coloniales no son cuerpos normalizados que se guían por la ley. Son cuerpos que están fuera de la ley: son deseo, naturaleza, violencia, amor fraternal o romántico. Aquellos que la ley quiere controlar, dominar, marginar.

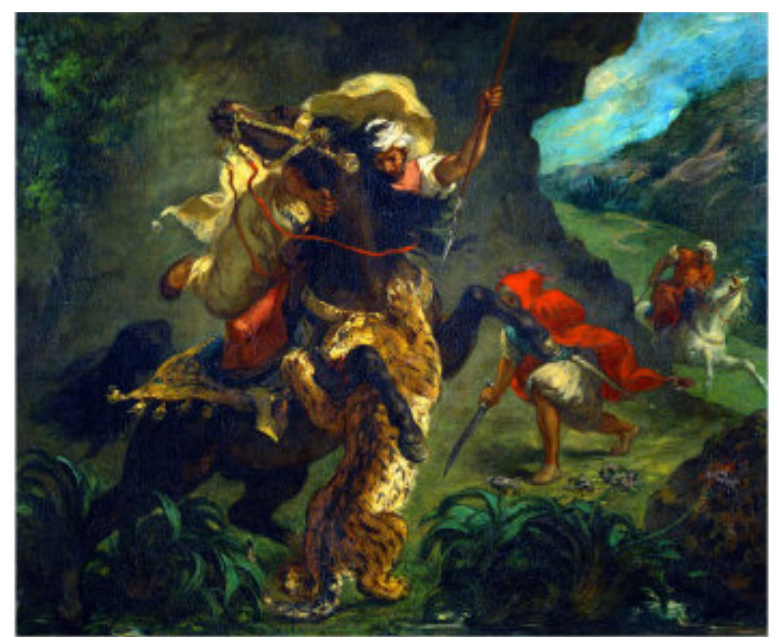

Figura 1. Eugène Delacroix (1798-1863): Chasse aux lions (La Casa del León).

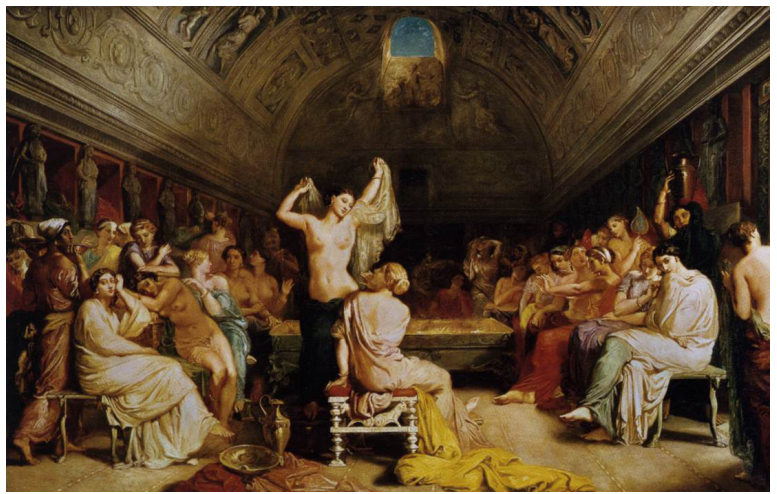

Figura 2. Théodore Chassériau (1819-1856): Tepidarium.

\subsection{El tiempo}

El tiempo que crea el modelo de producción colonial de conocimiento jurídico es lineal pero finito. El tiempo de la metrópoli se interpreta como una cadena valiosa y sólida que se pierde en el pasado, se vive en el presente y se mantendrá en el futuro. La tradición jurídica a la que pertenece la metrópoli se presenta como indudablemente fecunda. Esta tradición jurídica se entronca con una cultura compleja e inmemorial que se encarna en el derecho. La tradición civilista, por ejemplo, se presenta típicamente como el 
resultado del genio de la cultura romano-germánica (Monateri \& Samuel, 2006, p. 67).Las contribuciones que los sujetos coloniales han hecho a esta tradición, los judíos, los egipcios, por ejemplo, se hacen invisibles (Monateri \& Samuel, 2006, p. 67). La interacción con el otro se entiende como una contaminación. Las culturas se organizan jerárquicamente en directa relación con su capacidad de crear verdadero derecho. Existen culturas que tiene la posibilidad de crear derecho; otras que solo pueden reproducir su retraso.

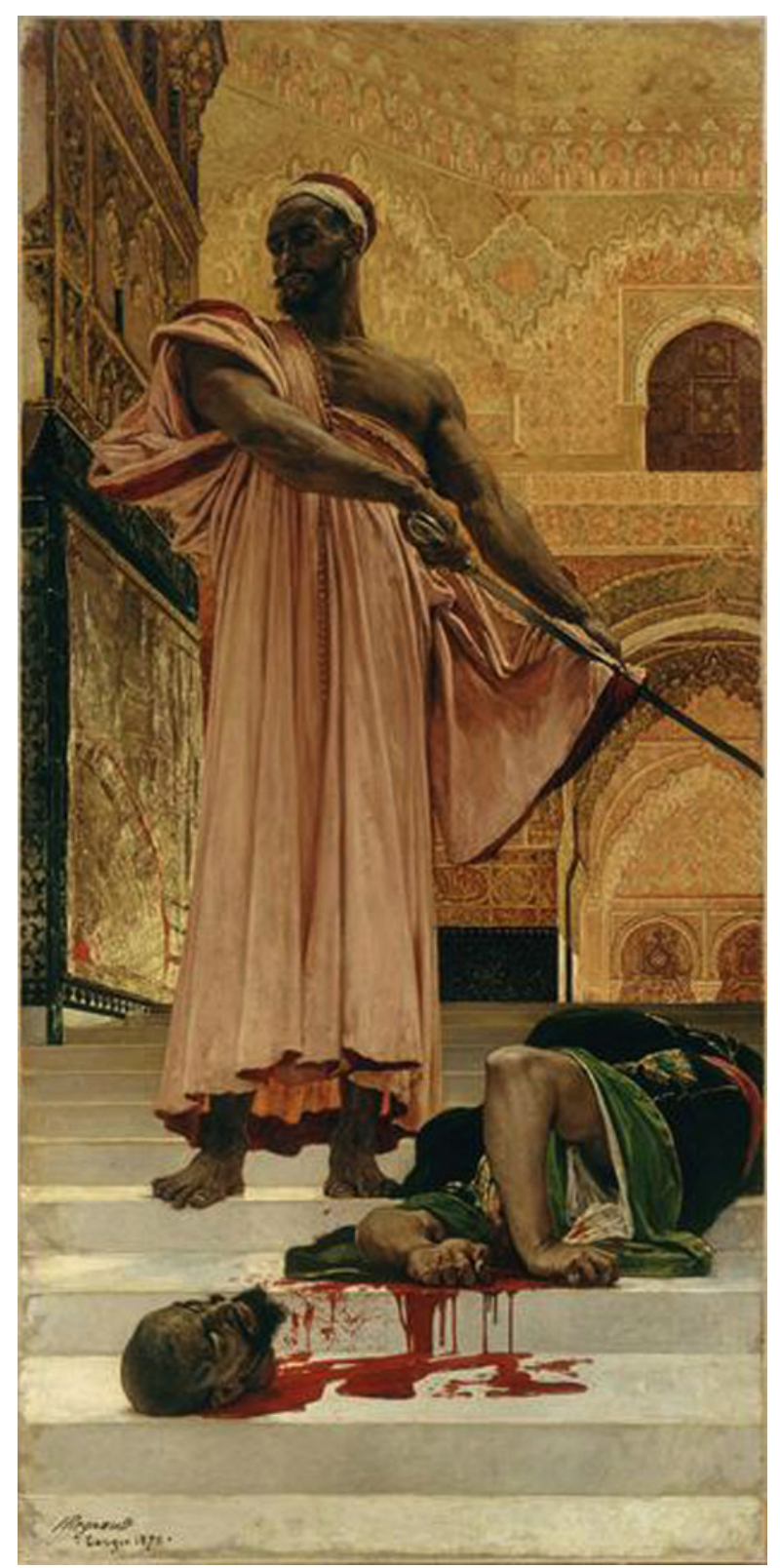

Figura 3. Henri Regault (1843-1871): Exécution sans jugement sous les rois maures de Grenade (Ejecución sin juicio bajo el mandato de los reyes moros en Granada).
La tradición jurídica de la metrópoli se inicia en un pasado remoto que se revive con sus constantes reinterpretaciones. Esta tradición, el tiempo en el que vive el sujeto-metrópoli, se concibe como una unidad. No tiene solución de continuidad; no está fraccionado; es uno. El sujeto-metrópoli lo experimenta como un todo en el presente. El futuro de este sujeto jurídico es mantener indefinidamente su presente. Mantener la metrópoli como metrópoli, que siempre estará definida por su otro, la colonia. La historia de la metrópoli, en un sentido particular, ya terminó. Ya es metrópoli. El tiempo del sujeto-metrópoli está en función del tiempo de la colonia y el sujeto colonial. Sin duda, seguirá enfrentando retos y dificultades jurídicos. No obstante, estos se presentan sobre la base y teniendo como trasfondo una tradición jurídica, un conjunto de instituciones y un ordenamiento que se presumen sólidos y a las que se llegó luego de un largo proceso histórico. No tiene sentido cambiarlas; son el derecho "metrópoli”, aquel al que las colonias aspiran llegar algún día.

El tiempo de la colonia, su historia, su pasado jurídico empieza con su interacción con la metrópoli. El pasado del sujeto colonial tiene un origen claro y distinto. Para el sujeto colonial antes de este encuentro no hay tiempo. Previo al momento cero se abre un vacío temporal; se sabe que algo hubo antes del inicio de la historia. Sin embargo, el modelo escoge ignorar ese hecho. El bajo valor jurídico de lo que antecede a la historia no merece atención. El derecho, la tradición jurídica de la colonia empieza con la conquista imperial. La historia del sujeto colonial, por tanto, es un continuo esfuerzo por ser como su otro. Por experimentar y superar cada una de las etapas que lo llevarán hasta el fin de su historia: el momento en donde no puede distinguirse de la metrópoli. El presente se muestra siempre como un eslabón en una cadena que termina en un punto definido. El futuro, como la posibilidad siempre abierta de llegar al final de la historia.

La experiencia latinoamericana con su pasado jurídico es ilustrativa a este respecto. Nuestra tradición legal, la que hoy en día ignoramos o intentamos aprehender a medias (nuestra producción sobre historia del derecho es insuficiente) (Mirow, 2004), comienza en el momento en que empieza nuestra interacción 
con Europa. Históricamente, nos hemos identificado como parte de la tradición romano-germánica (Clark, 1990). Las leyes coloniales, españolas o portuguesas, determinaron el inicio de nuestra historia jurídica. Las leyes de las repúblicas recién creadas no rompieron con esa tradición. El código civil de Andrés Bello, el documento jurídico por excelencia en la región, aquel que determina parte central de nuestra identidad jurídica, evidencia este hecho (Mirow, 2001). El Código de Bello es en buena parte una síntesis del Código Civil de Napoleón, las Siete Partidas de Alfonso el Sabio y el Digesto (Mirow, 2001, p. 304). Entramos en la historia del derecho como miembros secundarios de una tradición que no creamos. Ciertamente, nos hemos apropiado de esta tradición y la hemos transformado. Sin embargo, no se interpreta, no interpretamos, que estas apropiaciones y transformaciones hayan cambiado el curso de la tradición o se hayan convertido en representaciones de primer orden de los valores que esta promueve.

La situación se complejiza aun más si atendemos a la influencia que en las últimas décadas ha tenido la tradición jurídica angloamericana en la región (Kelemen \& Sibbitt, 2004, p. 103). La teoría del derecho liberal y crítica anglosajona, el valor de la jurisprudencia en el sistema de fuentes creadoras de derecho, el derecho penal adversarial, el derecho laboral neoclásico, los métodos de enseñanza y las formas de hacer academia jurídica estadounidenses, entre muchas otras cosas, han entrado sutil o abruptamente en nuestra historia jurídica (Merryman, 1977; Rittich, 2006). Nuevamente, interactuamos con la metrópoli y la historia del derecho de manera incómoda. Estas creaciones son en muchos sentidos nuestras. Hacen parte de nuestra realidad jurídica. Las hemos usado, interpretado y variado. Sin embargo, otra vez nos montamos en el vagón de la historia jurídica sin que hayamos podido llegar a su locomotora. No estamos en control de la tradición y nuestros productos se perciben, los percibimos, como expresiones menores de la misma. El carácter hibrido de nuestra tradición jurídica no es un problema; al contrario, es una oportunidad. No obstante, como sujetos de conocimiento entramos a esta historia siendo percibidos e interiorizando que nuestra historia jurídica empieza cuando hicimos contacto con el otro; siendo interpretados e interpretando como iteraciones menores de un pasa- do que realmente no nos pertenece y al que no hemos hecho aportes significativos.

Cuando intentamos mirar más atrás del momento cero de nuestra historia jurídica nos quedamos con las manos cuasi vacías. El pasado jurídico-político prehispánico no es casi completamente desconocido. No lo hemos hecho parte de nuestro presente. No quiere decir esto que normativamente debamos defender una especie de nativismo que valore únicamente aquello que sería percibido como original: las tradiciones jurídicas y políticas de los pueblos indígenas prehispánicos. Estas tradiciones pueden ser inútiles para las sociedades contemporáneas, cuestionables moral o políticamente o simplemente puede no haber información suficiente para evaluarlas y reinterpretarlas. Este nativismo negaría, además, nuestro ser jurídico criollo. Una parte de lo que somos jurídicamente está ya condicionado por las tradiciones jurídicas civilista y angloamericana. Parte de nuestra identidad legal está compuesta por los ejes que las constituyen. Estas tradiciones, además, tienen una riqueza innegable.

No obstante, parecería útil que Latinoamérica se reconectara críticamente con esa otra parte de su pasado jurídico que se ha hecho invisible. Algunos de los experimentos que hemos visto en Bolivia y Ecuador (Medici, 2010), por ejemplo, pueden ser prometedores. La idea de que la naturaleza tiene derechos, que los seres humanos podemos tener una relación no antropocéntrica con la naturaleza, el reconocimiento de la diversidad cultural dentro de las estructuras institucionales, entre otras cosas, pueden generar reinterpretaciones valioso de las tradiciones de los pueblos indígenas que sirvan a los Estados de la región a cumplir adecuadamente con sus fines (Gudynas, 2009). Este conocimiento puede entrecruzarse ricamente con los saberes jurídicos que ya hacen parte de nuestra historia y generar productos legales innovadores y útiles políticamente. Estos experimentos, además, pueden llevar a repensarnos como sujetos de conocimiento jurídico y a repensar el concepto de tiempo dentro del que nos movemos.

\subsection{El espacio}

El espacio del modelo de producción de conocimiento colonial es también dual. Esta cartografiado como 
un espacio Norte-Sur jerarquizado. El espacio no es horizontal; los espacios no se piensan como iguales. El contenido de cada uno de estas geografías es diferente y está calificado de manera distinta. El Norte Global, la metrópoli, es la tierra jurídica prometida; El Sur Global, la colonia, es tierra jurídica arrasada. La primera es un contexto rico de producción jurídica. Tiene las condiciones para crear, intercambiar y usar conocimiento jurídico. Tiene una tradición rica, unas instituciones académicas, jurídicas y políticas sólidas y unos sujetos adecuadamente preparados. Su historia muestra la infinidad de productos legales originales que ha creado y que ha exportado o podría exportar. En contraste, la segunda, el territorio colonial, es descrito por el modelo como un contexto pobre para la creación de conocimiento jurídico. Es un espacio de reproducción, difusión y aplicación local del conocimiento de la metrópoli. En esta geografía conceptual no se construye conocimiento original y no se cumplen con los requisitos mínimos para que esto suceda. Su tradición jurídica es inexistente o pobre, o es una pieza marginal dentro de la tradición de la metrópoli; sus instituciones jurídicas y políticas son débiles e inestables; y sus sujetos e instituciones de conocimiento están mal preparados y son frágiles.

Hasta hace muy poco, por ejemplo, los cursos y materiales de derecho comparado en las facultades de derecho de los Estados Unidos no incluían en el análisis a los países del Sur Global (Hirschl, 2014). Todavía hoy es excepcional encontrar que los programas de estas materias incluyan países diferentes a Alemania, Francia, el Reino Unido y, tal vez, Canadá (Hirschl, 2014). Es por esto, también, que cuando a un colega de una facultad de derecho de elite estadounidense se le preguntó si sería posible dictar un curso de derecho latinoamericano en su facultad hizo un gesto de incredulidad y desgano y contestó "¿a quién le interesaría?" De manera no anecdótica, los cursos sobre derecho latinoamericano, asiático o africano son la excepción en las facultades de derecho estadounidenses (Bonilla, 2013a, p. 11). Cuando, ocasionalmente se dictan, usualmente dependen de lo que se conoce como las area studies. Estudiar el derecho de un país del Sur Global puede ser pertinente para entender su estructura, dinámicas y características. Puede ser pertinente para los científicos sociales y humanistas que pertenecen a estos departamentos. Sin embargo, no lo es para los profesores de derecho. El derecho del Sur Global no es un objeto de estudio legítimo en las facultades de derecho del Norte Global.

Ahora bien, el espacio del modelo colonial está también jerarquizado internamente. El Sur también existe en el Norte, y en el Sur no todas las colonias son iguales. Para el modelo, puesto en operación, no es lo mismo Alemania, Francia y Estados Unidos que España, Portugal y Grecia; como tampoco es lo mismo India que Vietnam, Suráfrica que Namibia o Argentina que Nicaragua. El flujo del intercambio de bienes jurídicos en este espacio es, en consecuencia, unidireccional. El movimiento de la teoría, la doctrina y las prácticas jurídicas es siempre Norte-Sur; se da siempre en una sola dirección entre el espacio binario que es eje del modelo o dentro de cada uno de los espacios que constituyen a este eje.

\section{$4 \quad$ Las reglas y principios}

4.1 Las oposiciones conceptuales generales Las reglas y principios que guían al modelo giran en torno a las siguientes cuatro oposiciones conceptuales generales: mímesis/autopoiesis; conocimiento local/conocimiento universal; cultura/derecho; y lenguas aptas para el conocimiento jurídico/lenguas inútiles para el conocimiento jurídico. Estas oposiciones, van de la mano, con otras cuatro oposiciones conceptuales particulares: capital académico alto/ capital académico bajo; productos académicos de calidad/productos académicos de baja calidad; instituciones académicas ricas/instituciones académicas pobres; y experiencia para el uso del conocimiento jurídico/inexperiencia para el uso del conocimiento jurídico. Todas estas oposiciones conceptuales se entrecruzan creando un sistema que guía a los sujetos de conocimiento en sus procesos de producción, intercambio y uso de saber jurídico. Estas oposiciones conceptuales, además, dan origen a cinco presupuestos que precisan las maneras como los sujetos-metrópoli y sujeto colonial deberían comportarse. Estos presupuestos, en otros escritos, (Bonilla, 2013c) los he llamado "jerarquía de capital académico", "el que paga decide", "pozo de producción”, "denominación de origen calificado" y "operador eficiente".

La primera oposición conceptual general, mímesis/ 
autopoiesis, describe los contenidos de los sistemas jurídicos coloniales como representaciones de los sistemas jurídicos de la metrópoli. Aquellos, por tanto, aspiran volver a presentar (re-presentar) las teorías, doctrina y prácticas de estos. El derecho de la colonia es, en el mejor de los casos, una copia del derecho de la metrópoli. Esta es la máxima aspiración de la colonia. En tanto que su realidad jurídica y política no cumple con las condiciones necesarias para la creación de conocimiento jurídico no tiene opción distinta a imitar los productos jurídicos generados por su otro. Su mayor logro, por tanto, no puede ser distinto a copiar fielmente el original. Los problemas y retos que enfrentan la colonia y la metrópoli son análogos. Son consecuencia de que una y otra están compuesta por seres humanos que persiguen fines similares, por ejemplo, paz y prosperidad, y de que la naturaleza de la que están rodeados les genere retos análogos. ${ }^{26}$ Los conocimientos jurídicos de la metrópoli, por tanto, pueden ser exportados por la metrópoli e importados por la colonia. Los trasplantes jurídicos pueden, y deben ser, la regla (Tushnet, 1999). La colonia mimética, por tanto, es el espacio donde se difunde y aplica localmente el conocimiento original que surge en la metrópoli.

Una parte de la literatura sobre teoría jurídica en Latinoamérica sigue este patrón. ${ }^{27}$ Las publicaciones en el área son, muchas veces, intentos por explicar al público local la estructura argumentativa de la obra de los grandes filósofos del derecho angloamericanos (Medina, 2004). En esta medida los textos de teoría jurídica se presentan como una sumatoria de interpretaciones exegéticas y glosas explicativas que permiten que las nuevas generaciones de teóricos tengan acceso y conozcan el canon. Así, no es sorprendente encontrar que los anaqueles de teoría jurídica de las bibliotecas de derecho latinoamericanas contienen un número importante de libros sobre la teoría de, entre otros, Ronald Dworkin, H.L.A. Hart o Richard Posner. Muchos de estos libros no son diálogos horizontales entre el autor anglosajón y el autor latinoamericano. El texto no es un esfuerzo por

26 Para comprender adecuadamente este argumento se puede apelar al argumento análogo que ofrece el funcionalismo en derecho comparado (Tushnet, 1999).

27 Para un análisis de la teoría jurídica latinoamericana y su relación con la teoría jurídica del Norte Global, Véase Medina (2004). pensar juntos un problema teórico o práctico. El autor estadounidense es el referente en torno al cual gira el esfuerzo explicativo del autor latinoamericano. De partida se da una subordinación epistémica del segundo frente al primero. El punto no es negar que el trabajo de uno pueda ser más amplio y sólido que el del otro. Ciertamente, los autores anglosajones nombrados tienen una producción ilustre y tremendamente rica. El punto es exponer la actitud con la cual el académico latinoamericano asume su interlocución con el académico estadounidense. No se entiende, típicamente, como un par en el intento por describir, analizar o evaluar las realidades jurídicas de los Estados contemporáneos. Es un difusor del saber creado por otros.

En otras ocasiones, los textos de teoría jurídica latinoamericana buscan aplicar las teorías de los autores-metrópoli a sus propias realidades. El marco teórico está dado por la producción del autor anglosajón y los autores-colonia buscan hacer explícitas las consecuencias que tiene usarlo para describir, analizar y evaluar la realidad local. El argumento no es que sea problemático por sí mismo hacer uso de marcos teóricos foráneos para entender la realidad latinoamericana, aunque pueda serlo cuando estos marcos surgen de contextos muy diferentes a los contextos donde pretende aplicarse. El argumento tampoco pretende negar que en el uso puede haber transformaciones del discurso y, por tanto, innovación a través de la interpretación. El argumento es que la actitud con la que muchas veces se asume está impresa ilustra la oposición conceptual mimesis/autopoiesis. El autor latinoamericano no entra en diálogo con el marco teórico. No se entiende como parte de una narración que puede transformar, contribuir a desarrollar o criticar; su rol es el de aplicar y difundir de manera precisa un saber preexistente. Él está afuera de la narración y se relaciona con esta como un agente externo al saber que contiene.

El derecho de la metrópoli, en contraste, se entiende como un sistema original que surge como consecuencia y al mismo tiempo refleja la cultura metropolitana. La cultura, rica y compleja de la metrópoli, da lugar a un derecho particular que tiene como objetivo solucionar una serie de problemas sociales y políticos. Cultura y derecho en la metrópoli tienen 
una relación orgánica. ${ }^{28}$ Las reglas, principios, teorías y prácticas jurídicas expresan y confirman su cultura. Al mismo tiempo, el carácter autopoiético del sistema alude a su capacidad de reproducirse y transformarse. El orden jurídico tiene las herramientas para continuar existiendo como producto original y para transformarse sin perder esta originalidad. El sistema, ciertamente, tiene la capacidad de enriquecerse con elementos foráneos (y efectivamente lo hace). Empero, también tiene la potestad de apropiarse de esos elementos, de hacerlos propios, de transformarlos en un componente más de su maquinaria conceptual.

La oposición conceptual local/universal se entrecruza con el par mímesis/autopoiésis. El conocimiento de la colonia es interpretado como un conocimiento limitado espacialmente. Solo tiene aplicación dentro de las fronteras de la colonia; atiende únicamente a sus retos y realidades. No es reproducible en otros contextos. Un artículo sobre el derecho laboral mexicano o brasileño, por ejemplo, solo es relevante para México o Brasil. Nunca para Colombia, Suráfrica, India o Estados Unidos. Las realidades de los países del Sur Global no son generalizables. No son útiles, por su carácter específico, para otros países del Sur Global y mucho menos para los del Norte Global.

En contraste el saber de la metrópoli se entiende como universal. Por ende, a priori, tienen una relevancia y valor que trasciende las fronteras nacionales. De ahí que el saber de la metrópoli se considere ex ante trasplantable mientras que el saber de las colonias, ex ante, se considere enraizado en las realidades locales y, por tanto, incapaz de cruzar sus fronteras. El concepto de tiempo del modelo colonial explica este hecho. En tanto que el tiempo de la colonia es lineal y está compuesto por un conjunto de eslabones que termina en el derecho de la metrópoli, el conocimiento jurídico que genera es solo aplicable a sus condiciones particulares. Es solo relevante para la etapa de desarrollo jurídico en la que se encuentra. El tiempo de la metrópoli, el eterno presente que experimenta en el final de la historia, permite que el conocimiento que genera irradie y se aplique en to-

28 Para comprender el argumento se puede hacer una analogía con el argumento análogo que ofrecen las teorías expresivistas en derecho comparado. Véase, Legrand (1997). dos los eslabones de la cadena que le preceden. El saber de la metrópoli puede contribuir a que la colonia avance, progrese, en la materialización de su objetivo: ser como la metrópoli.

La recepción que ha tenido el trabajo de Ronald Dworkin y John Rawls en buena parte del Sur Global puede ser útil para ilustrar el argumento. Los dos filósofos reconocen explícitamente que su trabajo tiene como fuente el derecho y la cultura política estadounidense (Rawls, 1986). Sin embargo, su obra es leída, comentada y aplicada a lo largo y ancho del Sur Global sin que usualmente se haga referencia a la estrecha relación que tienen con un contexto particular. En las facultades de derecho latinoamericanas el trabajo de estos autores es omnipresente..$^{29} \mathrm{El}$ punto no es, claro, que en tanto que el derecho como integridad y el liberalismo político tienen un alto grado de abstracción no puedan viajar más fácilmente a través de las fronteras estatales que otros productos jurídicos y ser utilizados en contextos distintos al estadounidense. El punto es que el modelo colonial de producción de conocimiento jurídico hace que la conexión entre contexto y saber-metrópoli se pierda. Este conocimiento pareciera que existe en un vacío cultural y, por tanto, sea inmediatamente exportable y aplicable en cualquier contexto cultural. Este punto se vuelve aun más diciente cuando el conocimiento que es objeto de estudio es un conjunto de reglas o prácticas locales. Un artículo sobre derecho comercial, propiedad intelectual o derecho constitucional estadounidense también se entiende que tiene relevancia inmediata en el Sur Global. No importa que haga referencia a normas o prácticas particulares que solo tienen vigencia en Estados Unidos.

En contraste, el saber jurídico latinoamericano, asiático o africano se presume encadenado a sus contextos. Los artículos producidos en estas regiones generalmente aclaran en sus títulos y en sus contenidos que hablan del derecho chileno, egipcio o coreano. Se hace evidente desde el inicio que hace referencia y aplica única (o fundamentalmente) a un país. No obstante, es poco común encontrar que el título de una publicación de autoría de un profesor de derecho estadounidense diga algo así como "La libertad de

29 Véase Mattei (2003); y Wiegand (1996). 
expresión en Estados Unidos" o "La propiedad intelectual en los Estados Unidos”. En una ocasión un colega estadounidense luego de comentar uno de mis escritos me dijo que si lo quería publicar en una revista de derecho en su país debía agregar en el título la referencia a Colombia. En su concepto, ciertamente útil desde un punto de vista estratégico, debía ser claro cuál era el contexto nacional del que partía y en donde se desarrollaba mi análisis. Paradójicamente, ninguno de los varios escritos que este profesor ha publicado en Latinoamérica hace referencia a los Estados Unidos en el título. Ni el sintió la necesidad de hacer la aclaración ni los editores y editoriales sintieron la necesidad de pedirle que la hiciera.

El argumento que supone la universalidad del conocimiento jurídico del Norte Global también puede ilustrarse si se apela al papel menor que históricamente ha jugado la investigación empírica del derecho en Latinoamérica. Este rol menor puede explicarse por la falta de herramientas de investigación empírica que caracteriza al abogado latinoamericano y al legocentrismo que ha identificado a una parte importante de la academia jurídica de la región. En las facultades de derecho no es común que se enseñen los métodos de investigación empírica cualitativos y cuantitativos. Consecuentemente, los académicos del derecho típicamente no están familiarizados con estos métodos y no tienen experiencia en su puesta en práctica. En tanto que el objeto de estudio paradigmático del académico del derecho latinoamericano ha sido la ley, el producto por excelencia del trabajo académico es el tratado (Pérez-Perdomo, 2005, pp. 103-104). Este tipo de producto académico tiene como objetivo, en el mejor de los casos, sistematizar las normas que componen a un área específica del ordenamiento jurídico (Madrazo, 2008). En el peor de los casos, desafortunadamente muy común, tienen como fin presentar los contenidos de la ley con palabras distintas y agregar unas pocas glosas explicativas que generalmente van dirigidas a resolver un problema de la práctica jurídica.

Ahora bien, estos dos argumentos cuentan solo una parte de la historia. La ausencia del trabajo empírico en la academia jurídica latinoamericana también está relacionada con el uso de marcos teóricos que provienen del Norte Global y que se presumen uni- versales. En esta medida el académico del derecho asume que puede aplicar estas herramientas conceptuales sin atender a las particularidades de su contexto. Las diferencias de las realidades sociales son irrelevantes. El conocimiento teórico, dada su generalidad y racionalidad, puede usarse para describir, analizar o evaluar cualquier comunidad política. ${ }^{30} \mathrm{El}$ trabajo empírico que permite conocer las dinámicas y características de los contextos en donde surgen y se aplican las normas jurídicas resulta irrelevante.

La oposición conceptual cultura/derecho sugiere que en la colonia no hay realmente derecho, solo cultura, y un tipo de cultura particular. El derecho en la colonia ha fracasado (Esquirol, 2008) o es inútil. La cultura de la colonia no tiene las características que le permitirían crear un sistema jurídico que pudiera cumplir con los objetivos que usualmente intenta concretar, orden y justicia, por ejemplo. De esta forma, el derecho de la colonia y el conocimiento jurídico que lo tiene como objeto de estudio resulta irrelevante para la metrópoli. Los niveles de impunidad, por ejemplo, son tan altos que se considera que el derecho penal es irrelevante o marginal para mantener el orden social. Los niveles de seguridad, altos o bajos, que pudiera tener la colonia, por tanto, deben explicarse apelando a otros órdenes normativos, la moral secular o la religión, por ejemplo. Ningún sujeto de conocimiento de la metrópoli se interesaría por estudiar este conjunto de reglas jurídicas de papel.

Este argumento puede ilustrarse muy bien si se hace referencia a las descripciones que se hacen en las peticiones de asilo de muchos latinoamericanos en Estados Unidos (Esquirol, 2013). La estrategia que los abogados y organizaciones sociales articulan para que su representado consiga quedarse legalmente en Estados Unidos consiste en mostrar que el país de origen de quien busca asilo es tierra arrasada en materia jurídica (Esquirol, 2013). En este país no hay instituciones jurídicas y políticas funcionales y el derecho es solo una forma que tiene aplicaciones mínimas, si alguna, en la realidad social (Esquirol, 2013).

30 El uso que en muchas ocasiones se la ha dado en Latinoamérica a la obra de Jurgen Habermas evidencia como opera el argumento. Aunque Habermas menciona en su obra que su trabajo nace y se refiere a Europa Occidental, en Latinoamérica usamos sus modelos mecánicamente para examinar nuestros problemas. 
Las violaciones de los derechos humanos, por ende, son un patrón sistemático y continuo que toca toda la realidad social. No hay espacios en donde el derecho y las instituciones jurídicas y políticas funcionen. La cuestión no es que por razones estratégicas que pueden ser entendibles y loables, los abogados u organizaciones sociales describan la realidad del derecho latinoamericano de la manera anotada. La cuestión tampoco es argumentar que las violaciones de derechos humanos no son comunes en la región. El asunto sobre el que quiero llamar la atención con este ejemplo es que estas descripciones sin matiz alguno terminan construyendo la representación que la metrópoli tiene del derecho de la colonia y que esta termina interiorizando. Las cortes aceptan la tesis, los políticos la utilizan para generar políticas públicas y los académicos latinoamericanistas se benefician de ella cuando sirven a los abogados como expertos en los procesos (Esquirol, 2013). Este tipo de situaciones contribuyen a crear y recrear una visión homogeneizante de la realidad jurídica y política latinoamericana que la califica negativamente de manera absoluta. Esta visión, además, ayuda en la consolidación de la idea de que el derecho latinoamericano no es un objeto de estudio valioso, aunque su naufragio si lo sea.

Ahora bien, si el derecho fallido de la colonia resulta un objeto de estudio de segundo grado para los abogados y académicos del derecho de la metrópoli, este y los órdenes normativos que lo sustituyen resultan un objeto de estudio valioso para ciencias sociales como la antropología y la sociología de la metrópoli. ${ }^{31}$ Para estas ciencias tal situación genera un reto descriptivo y explicativo que puede rendir frutos epistemológicos notables. El supuesto del que parte esta oposición conceptual, entonces, es que hay una relación estrecha entre cultura y derecho y que hay algunas culturas que pueden crear derecho y otras que no. De ahí que el proceso civilizatorio que ha ido de la mano de muchas empresas imperiales empieza con un cambio cultural: los bárbaros deberán adoptar la religión, la lengua y las mores de la metrópoli. La barbarie jurídica tiene como una de sus principales causas la barbarie cultural.
En contraposición, en el modelo de producción de conocimiento jurídico colonial la metrópoli tiene derecho, no solo una apariencia de derecho. Este orden jurídico, además, refleja y es efecto de su cultura. Una cultura rica, compleja y sólida es precondición para la existencia de un verdadero ordenamiento jurídico. La relación entre derecho y cultura en la metrópoli es, por tanto, simbiótica. La cultura da lugar al derecho pero el derecho confirma y protege a la cultura. En el derecho comparado esta relación está firmemente enraizada. La tradición civilista se entiende como consecuencia, principalmente, de la cultura romano-germánica; la consuetudinaria de la cultura angloamericana (Schmidhauser, 1989). Las dos familias dominantes en la teoría y práctica del derecho comparado son fruto de dos tradiciones culturales de origen europeo (Pargendler, 2012). Las dos han sido (o fueron) relevantes en los proyectos imperiales tanto del Reino Unido como de Roma, Alemania, Francia y España (Schmidhauser, 1989).

La ultima oposición conceptual general, lenguajes apto para el conocimiento jurídico: lenguajes inútiles para el conocimiento jurídico hacen referencia nuevamente, pero de manera más precisa, a un elemento central de cualquier cultura: el lenguaje. El modelo de producción de conocimiento jurídico colonial entiende que los lenguajes de la metrópoli, español, portugués, inglés, entre otros, fueron o son herramientas finas y sutiles para expresar la verdad jurídica (Lillis \& Curry, 2010). Hoy en día, argumenta el modelo, esto es particularmente cierto respecto del inglés (Lillis \& Curry, 2010), dada la enorme influencia que tiene la teoría del derecho, la doctrina y las prácticas jurídicas anglosajonas en las comunidades jurídicas del Sur Global. El inglés se entiende como un lenguaje directo, preciso, flexible y que permite la creatividad de sus hablantes.

El inglés jurídico nombra las realidades de manera exacta y concisa. Hace un uso eficiente de sus recursos: sus frases son cortas y se pueden seguir fácilmente por el lector; sus párrafos distinguen adecuadamente entre las ideas que presentan y tienen un tamaño conveniente para que el interlocutor no pierda el hilo conductor. El inglés, además, se presenta como un lenguaje que es flexible frente a la realidad que nombra o califica, por ejemplo, al permitir la 
verbalización de sustantivos. Esto, a su vez, permite y promueve la creatividad de sus usuarios. Estos pueden fácilmente inventar palabras para nombrar la realidad que perciben o evalúan, por ejemplo, para captar sus matices o designar un nuevo fenómeno. Por el contrario, lenguajes como el español se entienden como imprecisos e ineficientes. El español, por ejemplo, se describe como un lenguaje que no conoce el principio de la economía de medios: sus frases largas, sus párrafos interminables, sus descripciones haciendo uso de un número infinito de palabras. Un lenguaje, se concluye, poco útil para expresar el conocimiento jurídico. Estas descripciones del inglés y el español, como puede verse, en ocasiones se presentan como componentes centrales del lenguaje mismo; en otras, como convenciones sobre las formas en que se usan estos lenguajes en la academia jurídica.

Los latinoamericanos que han estudiado o trabajado en una facultad de derecho estadounidense probablemente habrán oído este tipo de descripciones del español. En esta medida muchos de estos practicantes o académicos invierten una gran cantidad de tiempo y esfuerzo en modificar las convenciones para la expresión de las ideas con las que se formaron. Esto, sin duda, puede ser provechoso. Permite que estos abogados latinoamericanos se acerquen a formas de expresión diferentes que pueden generar réditos distintos a los que crean las convenciones lingüísticas y de locución académica que conocen. El problema surge cuando estas convenciones y prácticas se esencializan y se naturalizan. La cuestión probablemente se explicaría mejor diciendo que el abogado latinoamericano simplemente no tiene un manejo adecuado del inglés y está expresando sus ideas haciendo uso de palabras de este idioma pero con formas gramaticales propias del español. Esto sin duda es un error que hay que corregir. No obstante, esta situación no se presenta siempre como un problema práctico que se resuelve con trabajo y esfuerzo del hispanohablante sino como características de su lenguaje y, por tanto, de su cultura. De la situación anterior no se puede derivar que el español no pueda ser un vehículo adecuado para la expresión de conocimiento jurídico claro y preciso.

Este problema se agudiza cuando se hace explicito que las discusiones y publicaciones académicas más pres- tigiosas tienen como lenguaje oficial único al inglés y están principalmente localizadas en Estados Unidos (Lillis \& Curry, 2010). El académico del Sur Global que no tiene el inglés como su lengua madre tiene un doble reto: hacerse competente en una lengua que no es la suya y aprender las convenciones estadounidenses para la investigación, redacción y presentación de los trabajos académicos en derecho. En los debates académicos verbales esta carga resulta particularmente onerosa. Por un lado, al abogado del Sur Global no anglófono se le exige que hable en un lenguaje que no es el suyo en tanto que es el idioma "internacional"; por el otro, para que sea tomado medianamente en serio se le pide que tenga las mismas competencias lingüísticas que sus colegas anglófonos. La lentitud, imprecisión o mala pronunciación no siempre se tolera.

Nuevamente, quienes han estudiado o trabajado en una facultad derecho estadounidense probablemente alguna vez habrán visto como sus colegas anglófonos se dispersan, angustian o voltean sus ojos cuando al presentar sus ideas las frases se vuelven muy largas, sus palabras vagas o las fallas en su pronunciación se vuelven recurrentes. Esta situación contrasta con el hecho de que el número de profesores de derecho estadounidenses que hablan una segunda lengua no es muy alto. En esta medida no han tenido que experimentar el esfuerzo que implica aprender otro idioma, asimilar las convenciones académicas a través de la cuales se expresan otras comunidades de saber o sentir la desazón que surge al equivocarse o ser impreciso cuando se habla en círculos profesionales un idioma que no es el propio. También contrasta con el hecho de que es usual que los esfuerzos del académico del Norte Global por hablar el idioma del país del Sur Global que visita sean recibidos con alborozo, así sean fallidos, o que se asuma que el profesor del Sur Global, en su país, debe hablar inglés con el profesor estadounidense, así este hable el idioma local.

\subsection{Las oposiciones conceptuales particulares}

Las cuatro oposiciones conceptuales particulares hacen referencia directa y explícita a los contextos de creación de conocimiento de la colonia y la metrópoli. Estas oposiciones conceptuales se nutren y, al mismo alimentan, a las cuatro oposiciones conceptuales 
generales. Todas ellas constituyen un entramado conceptual que debe explicar y guiar a los sujetos de conocimiento jurídico. Estas oposiciones conceptuales específicas son las siguientes cuatro: capital académico alto/capital académico bajo; productos académicos de calidad/productos académicos de baja calidad; instituciones académicas ricas/instituciones académicas pobres; y experiencia para el uso del conocimiento jurídico/inexperiencia para el uso del conocimiento jurídico.

La primera oposición conceptual hace referencia a las diferencias que existen entre la metrópoli y la colonia con respecto al capital académico del que cada una de ellas dispone. La primera se entiende como un espacio que dispone de un capital académico alto. Sus instituciones universitarias son más sólidas que las de la colonia. Esta solidez se evidencia en dimensiones tanto cuantitativas como cualitativas (Bonilla, 2013c, pp. 6-9). De un lado, el número de profesores de tiempo completo, el número de bases de datos, la cantidad de libros en las bibliotecas, la cantidad y variedad de publicaciones y el elevado número de intercambios académicos con redes nacionales o internacionales. De otro lado, la calidad de la producción académica, la interiorización y aplicación sistemática por parte de los miembros de la comunidad académica del derecho de una serie de dinámicas para la producción, discusión y difusión de los productos que se generan y la calidad de la infraestructura de la que disponen los profesores de derecho. En contraste, en la colonia, el modelo asume que el capital académico del que se dispone es bajo, igualmente, por razones cuantitativas y cualitativas (Bonilla, 2013c, pp. 6-9). La profesionalización de la academia jurídica es reciente $\mathrm{y}$, por ende, hay muy pocos profesores de tiempo completo y el número de libros, publicaciones, y redes académicas nacionales e internacionales disponibles es muy bajo. Asimismo, las dinámicas de producción y crítica que permiten la creación sistemática de conocimientos jurídicos no existen o no se han sistematizado o interiorizado por parte de la academia jurídica colonial. La calidad de la estructura material a la que tienen acceso los profesores de derecho, edificios, computadores, bases de datos, entre otros, no es la adecuada.

Esta primera oposición conceptual va de la mano de las dos siguientes: instituciones académicas ricas/ instituciones académicas pobres y productos jurídicos de alta calidad/productos académicos de baja calidad. Las comunidades académicas de la metrópoli, en parte, deben su capital académico alto a la gran cantidad de recursos económicos que tienen a su disposición. Esto permite cubrir los costos notables que tiene, por ejemplo, contratar profesores de tiempo completo, tener buenas bibliotecas y construir y participar en redes académicas nacionales e internacionales. Esto igualmente les permite hacer mayores contribuciones a los proyectos académicos adelantados conjuntamente con instituciones del Sur Global, la organización de seminarios, investigaciones que incluyen trabajo de campo o la publicación de libros, por ejemplo. La falta de recursos económicos explica parcialmente las debilidades de las facultades de derecho del Sur Global y su menor contribución material a los proyectos que adelantan en alianza con instituciones académicas de la metrópoli.

Si se comprenden estas tres oposiciones conceptuales, no resulta sorprendente, por tanto, que para el modelo los productos de calidad de la colonia se presuman como de baja calidad y que los productos de la metrópoli se presuman como de alta calidad. Las condiciones materiales e inmateriales (cultura académica) de las que parten cada una son muy distintas. De una tierra yerma académicamente no pueden surgir frutos apetitosos para la mente; de una tierra académica fértil y bien cultivada surgirán cosechas gustosas para las cabezas inquietas intelectualmente.

Estas tres oposiciones conceptuales generan, a su vez, tres premisas que guían (y deben) guiar al sujeto de conocimiento del modelo colonial: pozo de producción, denominación de origen controlado y el que paga decide (Bonilla, 2013c, pp. 7-13). Estas premisas indican que la única fuente posible de creación de conocimiento jurídico es el Norte Global; que los productos jurídicos de la metrópoli por provenir de la metrópoli deben presumirse que tienen una calidad alta; y que aquel que contribuye con más recursos a la financiación de un proyecto conjunto Sur-Norte debe gozar de un poder de decisión mayor sobre sus fines y desarrollo.

La primera premisa, el pozo de producción, explicaría por qué en la construcción e interpretación de la 
gramática del constitucionalismo moderno los académicos y cortes del Sur Global han jugado un papel marginal (Kahn, 1999, p. 12). Estas y aquellos están en las orillas del diálogo global que se da en torno al significado y consecuencias prácticas que deben tener conceptos como pueblo, soberanía, ciudadanía, derechos, igualdad y autonomía (Tully, 1997). Estos conceptos, construidos por un conjunto relativamente pequeños de teóricos modernos y contemporáneos, como Thomas Hobbes, Jean Jacques Rousseau, John Locke e Immanuel Kant, de un lado y John Rawls, Charles Taylor, Robert Nozick y Jurgen Habermas, por el otro, constituyen los ejes en torno a los cuales gira la imaginación jurídica y política moderna (Tully, 1997; Mcllwain, 1940). No obstante dentro de aquellos que se presumen intérpretes legítimos de estas categorías no aparecen casi nunca los sujetos de conocimiento coloniales. Cuando se habla de intérpretes contemporáneos legítimos de esta gramática constitucional aparecen instituciones como la Corte Suprema de los Estados Unidos, la Corte Europea de Derechos Humanos o la Corte Constitucional alemana. Aparecen igualmente autores como Ronald Dworkin, Cass Susstein o Richard Posner. No obstante, pocos pensarían que instituciones como la Corte Suprema India, la Corte Constitucional Surafricana o la Corte Constitucional colombiana o cualesquiera que se consideren los más sólidos académicos del derecho del Sur Global han jugado o podrían jugar un papel análogo al de los autores o instituciones del Norte Global.

La segunda premisa explicaría por qué es común que en los seminarios sobre temas jurídicos en Latinoamérica los profesores estadounidenses sean invitados como conferencistas centrales o jueguen, de facto, un papel capital. No importa a que institución pertenece y si esta es o no sólida; tampoco importa mucho la calidad de su producción académica. No es común que en la academia jurídica latinoamericana se tenga información precisa sobre la gran mayoría de las facultades de derecho estadounidenses. La información que se cuenta sobre las facultades distintas a las que ocupan los primeros puestos en los rankings académicos es mínima. Todos los profesores de derecho latinoamericanos conocen a Yale, Harvard, Stanford o Columbia pero muy pocos tienen conocimientos precisos sobre la mayor parte de las facultades de derecho que ocupan las capas medias y bajas de las jerarquías académicas estadounidenses. Tampoco se tiene mucha información precisa sobre el trabajo de los académicos que no pertenecen a las universidades del Ivy League. No obstante, las premisas del pozo de producción y denominación de origen calificado hacen que la calidad alta de los mejores productos jurídicos estadounidenses envuelva al mismo tiempo, sin justificación empírica, los otros productos jurídicos que surgen en las facultades de derecho de este país.

Lo que en estos casos resulta importante para los organizadores de muchos seminarios es el contexto de producción de conocimiento del que proviene el profesor y que su producción está escrita en inglés y publicada en revistas o editoriales estadounidenses. Como el vino de borgoña, este profesor y su producción, gozan de una presunción de calidad que lo protege y lo valora aun antes de que se lea y evalúe efectivamente su trabajo. Ahora bien, la cuestión es que una vez se prueba, este vino (este trabajo) puede estar picado, tener altos grados de acidez o un grado excesivo de taninos. Esta premisa también explica, para ser más concretos y volver a la introducción de este artículo, porque en el seminario sobre educación jurídica experiencial en una universidad de elite brasileña los invitados centrales del evento eran dos profesores estadounidenses que pertenecían a una institución débil y cuya producción académica no era particularmente destacada. El criterio fundamental que determinó su invitación y posición privilegiada en el evento, por encima de profesores latinoamericanas con una producción más sólida que estaban en la audiencia o en los paneles, fue el del contexto de producción de conocimiento jurídico del que provenían, esto es, la puesta en operación de los presupuestos del pozo de producción y denominación de origen calificado.

Estos dos presupuestos, de la mano con las oposiciones conceptuales conocimiento universal: conocimiento local y autopoiesis/mímesis, también explican porque una sentencia como Roe vs. Wade es reconocida y valorada positivamente como producto jurídico en buena parte del Sur Global. Esta sentencia, es argumentable, no es formal o sustantivamente mejor como producto de conocimiento 
jurídico que las sentencias alemanas o colombianas que despenalizan el aborto parcialmente o la canadiense que lo hace totalmente. En cualquier caso no es un producto jurídico de calidades extraordinarias formales o sustanciales. El momento histórico en el que se expide Roe, sin duda, es un factor que permitió su reconocimiento: es una de las primeras sentencias que despenalizaron el aborto en el mundo. Sin embargo, estas variables sólo explican parte de la historia. Es común que tanto los defensores como los detractores del aborto en la academia colonial puedan hacer referencia a Roe. No obstante, no es común que académicos no especializados en el tema puedan aludir a las sentencias de Alemania, Canadá o Colombia sobre el tema. Para explicar el reconocimiento muy amplio que ha alcanzado la sentencia habría también que señalar que fue expedida por la Corte Suprema de Justicia estadounidense y que ha sido descrita y evaluada infinidad de veces por profesores estadounidenses en sus escritos académicos. Asimismo, habría que mencionar que los Estados Unidos se entienden como el pozo de producción de conocimiento jurídico por excelencia desde al menos la segunda mitad del siglo XX (Langer, 2014, p. 1).

La premisa del que paga decide, siguiendo con la ilustración de los presupuestos del modelo colonial de producción de conocimiento jurídico, se pone en operación continuamente en los proyectos conjuntos que realizan profesores de las facultades de derecho estadounidense y las facultades de derecho del Sur Global. Los proyectos clínicos como las llamadas fact-finding missions son útiles para mostrar cómo funciona esta premisa (Bonilla, 2013c, pp. 21-25). El objetivo de este tipo de proyectos, típicamente, es describir de manera precisa y completa la violación de derechos humanos en una zona del Sur Global. En estos proyectos una facultad de derecho estadounidense y una organización social o una facultad de derechos del Sur se alían para adelantar el trabajo (Bonilla, 2013c, pp. 21-25). Ahora bien, usualmente, aquella es quien aporta una mayor cantidad de recursos económicos para financiar el proyecto. El dinero para financiar el trabajo de campo, por ejemplo, generalmente viene de la institución académica del Norte. Las premisas del modelo colonial de conocimiento jurídico, consecuentemente, aceptan y promueven que, dadas estas circunstancias, la ins- titución de la metrópoli sea la que decida la estructura y fines básicos del proyecto. Esta situación, no obstante, oscurece las contribuciones que hacen las instituciones coloniales y que son necesarios para el éxito del programa: contacto con la población local e información académica que describe, analiza y evalúa el objeto de estudio de la misión.

La última oposición conceptual particular, experiencia para el uso del conocimiento jurídico: inexperiencia para el uso del conocimiento jurídico, hace referencia a quién se considera un agente legítimo para poner en operación ética y eficientemente los productos jurídicos que se generan en la metrópoli y la colonia (Bonilla, 2013c, pp. 21-25). Esta oposición conceptual genera el presupuesto del operador eficiente. Para el modelo de producción de conocimiento jurídico colonial el sujeto de saber de la metrópoli tiene el know how para hacer un uso eficaz de los productos jurídicos, demandas, informes, artículos, por ejemplo. Paralelamente entiende que este sujeto ha interiorizado las reglas de ética profesional que existen en su comunidad jurídica. En contraste, el sujeto de conocimiento colonial se comprende como un sujeto ineficaz e ingenuo o débil éticamente para al uso del conocimiento jurídico. No tiene los contactos en las redes nacionales o internacionales para que el conocimiento creado pueda generar un impacto. Sus comunidades jurídicas no tienen o no aplican reglas de ética profesional y el mismo no tiene la capacidad o la voluntad de hacerlo.

Las oposiciones conceptuales descritas y el concepto de sujeto, tiempo y espacio del modelo colonial de producción de conocimiento jurídico se explican por el conjunto de razones que se presenta a continuación. La primera de ellas es la relación imperial directa o indirecta que el Norte Global ha tenido con el Sur Global (Anghie, 2004; Mickelson, 2000). Las relaciones imperiales de España, Portugal, Reino Unido, Alemania, Italia, Francia, Bélgica y Estados Unidos, entre otros, con Latinoamérica, Asia y África son bien conocidas y han tenido como uno de sus principales instrumentos para su consolidación y desarrollo al derecho (Koskenniemi, 2001). El derecho de Indias y el concepto de terra nullius son ejemplos bien de cómo el derecho fue una herramienta importante en los procesos de conquista y colonización del Sur 
Global (Gilbert, 2006). La idea de que los imperios coloniales son los troncos de los cuales surgen las principales tradiciones jurídicas (Santos, 1995; Hoecke \& Warrington, 1998) también juega un papel importante para explicar la existencia del modelo colonial de producción de conocimiento jurídico (Santos, 1995; Mattei, 1997; Hoecke \& Warrington, 1998). Latinoamérica se entiende como un miembro menor de la tradición civilista (Esquirol, 1997; 2003; 2008), África (Nkrumah, 1962) y Asia, ${ }^{32}$ dependiendo del imperio que haya controlado los distintos territorios que los componen, se entienden como una iteración marginal de la tradición consuetudinaria o de la civilista. Asimismo, Europa del Este se entiende como una reproducción menor de derecho socialista obsoleto e importaciones contemporáneas de derecho de Europa occidental o Estados Unidos (David \& Brierley, 1978, pp. 222224). En algunos de los países que componen a estas regiones la tradición de la metrópoli, transformada y reinterpretada, coexiste con un derecho nativo. Sin embargo, típicamente, este se subordina al legado de la metrópoli o se considera de una calidad menor.

Esta razón explicativa tiene una consecuencia epistemológica poderosa: hace que el derecho del Sur Global no sea considerado un objeto de estudio valioso y que el saber jurídico que lo tiene como su objeto de estudio sea considerado marginal o irrelevante. Si se quiere describir, analizar o evaluar a las grandes tradiciones jurídicas del mundo, se argumenta, habría que examinar el derecho de los países que las originaron, desarrollaron o transformaron. No resulta útil o eficiente analizar aquellos ordenamientos jurídicos que son meras copias o reinterpretaciones menores de estas tradiciones.

Esta perspectiva se consolida cuando se conecta con la influencia enorme que ha tenido el derecho estadounidense en las últimas décadas a lo largo y ancho del Sur Global (Merryman \& Pérez-Perdomo, 2007; Kelemen \& Sibbitt, 2004; Merryman, 1977; Rittilich, 2006). Este segundo argumento apunta nuevamente a mostrar que la teoría, doctrina y prácticas jurídicas del Sur Global son copias más o menos fieles del de-

32 This inherited or imported law from the colonial cities coexists with the religious legal traditions in many countries in the region, Islamic or Buddhist ones in particular (Abu-Odeh, 2004). recho del Norte Global. La exportación de paquetes jurídicos por parte de Estados Unidos ha hecho que una parte importante del derecho de Latinoamérica, Asía y África no pueda distinguirse en lo fundamental del derecho estadounidense. El derecho penal acusatorio (Domingo \& Sieder, 2001; Torres, 2007), el derecho laboral liberal clásico (Murillo, 2007), las normas de propiedad intelectual que se adoptan como consecuencia de los tratados de libre comercio (Morin \& Gold, 2013) y el derecho societario que protege a las empresas multinacionales (Spamann, 2010) son solo algunos ejemplos de este argumento. Todos estos son trasplantes jurídicos que vienen de los Estados Unidos y que tienen una dirección Norte-Sur. ${ }^{33}$ Por consiguiente, el derecho del Sur Global otra vez se presenta como un objeto de estudio poco atractivo. Las copias no tienen nunca el valor que tiene el original.

El modelo colonial de conocimiento jurídico se explica también por una descripción del derecho del Sur Global como homogéneamente formalista. El concepto de derecho dominante en los ordenamientos jurídicos de Asia, ${ }^{34}$ África, ${ }^{35}$ Europa del Este ${ }^{36}$ y Latinoamérica $^{37}$ se describe como uno comprometido con la idea de que los sistemas jurídicos son cerrados, completos, coherentes y unívocos. Esta descripción, el tercer argumento explicativo, genera a su vez una práctica ritualista del derecho que lo hace tremendamente ineficiente y que no satisface las necesidades jurídicas de los ciudadanos (Merryman \& Pérez-Perdomo, 2007; Atienza, 2003, pp. 276-279). La relación entre concepto de derecho, educación jurídica y academia jurídica complica aun más las cosas. El concepto de derecho formalista, se argumenta, genera una educación jurídica y una academia jurídica formalistas (Olea, 2013, p. 268).

Las facultades de derecho se construyen a partir del legocentrismo, el enciclopedismo y el memorismo. ${ }^{38}$

33 Véanse Davis (2003); Epstein \& Knight (2003); Hasebe (2003); Osiatynski (2003); Rosenkrantz (2003); Scheppele (2003).

34 Véase Ginsburg \& Chen (2009; 2003).

35 Véase Chanock (2001); Nolutshungu. (1993).

36 Véase, Matczak (2007).

37 Véase Merryman \& Pérez-Perdomo (2007).

38 Véanse, Hurtado (2010); Fierro \& López (2006); Vargas (2009). Véase Igualmente, Desafíos para La Educación Legal en América Latina: Documentos de Trabajo del Encuentro Educación Legal en América Latina: Nuevos Desafíos a las Facultades de Derecho, 2004. 
Esta enseñanza jurídica, por tanto, es indiferente a los análisis contextuales o críticos de las normas jurídicas y tiene como su herramienta pedagógica única a la clase magistral. El concepto formalista del derecho hace que el profesor de derecho, a su vez, entienda que su función primordial es la de sistematizar las normas jurídicas. ${ }^{39}$ De esta forma, sus productos académicos paradigmáticos son intentos por estructurar un campo del derecho de manera que los límites conceptuales de cada categoría sean claros y precisos y que las relaciones jerárquicas u horizontales de las normas jurídicas que lo componen queden claramente establecidas. Las debilidades de este concepto y prácticas académicas formalistas se profundizan si las entrecruzamos con los problemas cuantitativos y cualitativos que tiene la academia jurídica de las colonias y que se mencionaron arriba (Pérez-Perdomo, 2005). Este argumento, que constituye la cuarta razón explicativa, hace referencia a las debilidades en cuanto al número y calidad de la producción académica de las colonias (Bonilla, 2013c), así como a la ausencia de las condiciones materiales e inmateriales que permitirían la creación de un conocimiento jurídico verdaderamente original.

Finalmente, el modelo colonial de producción de conocimiento jurídico se explica por la supuesta autosuficiencia de los sistemas jurídicos de la metrópoli (Mattei, 1998). Estos, así como la academia jurídica que los estudia, no tienen la necesidad de mirar más allá de sus límites, al Sur Global, para solucionar los problemas legales y políticos que enfrentan. El Sur Global, se presume, tiene muy poco que enseñarle al Norte Global. De ahí que el derecho comparado, como área de estudio, históricamente haya mirado fundamentalmente al derecho de las metrópolis no al derecho de las colonias. De ahí que las comunidades jurídicas y académicas del Norte Global se describan como centradas en sí mismas y parroquiales.

\section{Conclusión}

La economía política de la producción, intercambio y uso del conocimiento jurídico es un tema poco explorado por la academia jurídica. No obstante, su teoría y práctica determinan la manera como describimos, analizamos y evaluamos estos procesos. Estos, a su vez, tienen relevancia no solo para los académicos del derecho que están localizados en el centro de tales actividades. Tienen importancia también para los políticos, organizaciones sociales y ciudadanos que son sujetos activos y pasivos del conocimiento jurídico. El saber jurídico viaja constantemente a través de las fronteras y tiene efectos prácticos importantes para todos los miembros de la comunidad política. Es la fuente de normas, teorías y prácticas jurídicas que generan de manera directa o indirecta derechos y obligaciones.

El modelo del libre comercio de las ideas jurídicas y el modelo colonial de producción de saber jurídico dan cuenta de estos procesos y a la vez les sirven de guía. El primero, en parte porque es un componente de la maquinaria conceptual de la modernidad ilustrada y liberal con la que ya estamos comprometidos, domina nuestra imaginación jurídica y política normativa. Los conceptos de sujeto, tiempo y espacio que estructuran el modelo condicionan la manera como pensamos que deberían darse los procesos de creación del saber jurídico. Este modelo, asimismo, guía algunos de las dinámicas que los controlan en la práctica. Sin embargo, este compite por controlar nuestra imaginación con el modelo colonial de producción de conocimiento jurídico. El modelo colonial también ocupa un lugar en nuestra imaginación jurídica y política, aunque usualmente este sea periférico. No es común encontrar una defensa explícita de sus conceptos de sujeto, tiempo y espacio. Este modelo, no obstante, ofrece una mejor explicación de las prácticas que efectivamente determinan como se crea, intercambia y usa el conocimiento legal. Sus categorías centrales efectivamente determinan nuestras acciones, aunque sea de manera vergonzante. Para entender quiénes somos como sujetos de conocimiento jurídico, por ende, debemos entender y analizar los ejes que constituyen a cada uno de estos modelos. Su evaluación y eventual transformación dependerá de que este primer paso se cumpla de manera apropiada.

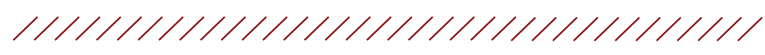




\section{Referencias}

Abu-Odeh, L. (2004). The Politics of (Mis)recognition: Islamic Law Pedagogy in American Academia. American Journal of Comparative Law, 52.

Alejandro Madrazo, A. (2008). From Revelation to Creation: The Origins of Text and Doctrine in the Civil Law Tradition. Mexican Law Review, 1(1).

Anghie, A. (2004). Imperialism, Sovereignty and the Making of International Law. Cambridge: Cambridge University Press.

Aparicio, M. (2011). Nuevo constitucionalismo, derechos y medio ambiente en las constituciones de Ecuador y Bolivia. Revista General de Derecho Público Comparado.

Atienza, M. (2003). El sentido del derecho. Barcelona: Ariel.

Balkin, J. (2011). Constitutional Redemption: Political Faith in an Unjust World. Cambridge: Harvard University Press.

Bensusán, G. (2007). La efectividad de la legislación laboral en América Latina, Instituto de Estudios Laborales. Organización Internacional del Trabajo. Disponible en http://www.ilo.org/public/spanish/ bureau/inst/download/dp18107.pdf.

Bergel, J. L. (1988). Principal Features and Methods of Codification. Louisiana Law Review, 48(5), 10731097.

Bonilla, D. (2013a) Introduction, In D. Bonilla (Ed.), Constitutionalism of the Global South: The Three Activist Courts of India, South Africa and Colombia. Cambridge: Cambridge University Press.

Bonilla, D. (2013b). El formalismo jurídico, la educación jurídica y la práctica profesional del derecho en Latinoamérica In H. Olea (Ed.), Derecho y pueblo Mapuche. Universidad Diego Portales.

Bonilla, D. (2013c). Legal Clinics in the Global North and South: Between Equality and Subordination. Yale Human Rights and Development Law Journal, 16(1).

Bonnecase, J. (1944). La Escuela De La Exégesis En El Derecho Civil. México: Cajica.

Boucher, D., \& Kelly, P. (Eds.) (1994) The Social Contract from Hobbes to Rawls. New York: Routledge.

Cappelleti, M., \& Garth, B. (1996). El acceso a la justicia. La tendencia en el movimiento mundial para hacer efectivos los derechos, México: Fondo de Cultura Económica.

Clark, B. C. (1998). Political Economy: A Comparative
Approach. Westport: Praeger.

Coetzee, J. M. (2003). Esperando a los bárbaros. México: Random House Mondadori.

Cummings, S. L. (2004). The Politics of Pro Bono. UCLA Law Review, 52, 1-149.

Cummings, S. L., \& Rhode, D. L. (2010). Managing Pro Bono: Doing Well by Doing Better. Fordham Law Review, 78(5), 2357-2442.

David R., \& Brierley, J. E. (1978). Major Legal Systems in the World Today. New York: Free Press.

Davis, D. M. (2003). Constitutional Borrowing: The Influence of Legal Culture and Local History in the Reconstitution of Comparative Influence: The South African Experience. International Journal of Constitutional Law, 1, 181-195.

Dean, W. (2004). Pro Bono: A Professional and Ethical Obligation. New York Law Journal. Disponible en: http://www.probono.net/ny/ news/article.47740Pro_Bono_A_Professional_and_Ethical_Obligation.

Dewey, J. (1924). Logical Method and the Law. Cornell Law Quarterly, 10.

Domingo, P., \& Sieder, R. (2001). Rule of Law, in Latin America: The International Promotion of Judicial Reform 1. London: Institute of Latin American Studies.

Dominguez, F. R., \& Baert, P. (Eds.) (2000). The Politics of Knowledge. London: Routledge.

Donnelly, J. (2003). Universal Human Rights In Theory And Practice. Ithaca: Cornell University Press.

Duce, M. (2008). Enseñando destrezas de litigación en procesos orales en la Universidad Diego Portales: experiencias y aprendizajes. Derecho y Democracia - 15 Cuadernos Unimetanos, 91-107.

Dupré, L. (2004). The Enlightenment and the Intellectual Foundations of Modern Culture. New Haven: Yale University Press.

Dworkin, R. (1986). Law's Empire. Cambridge: Harvard University Press.

Elster, J. (1998). Régimen de mayorías y derechos individuales, En De los Derechos Humanos: Las conferencias Oxford - Amnesty de 1993. Madrid: Editorial Trotta.

Epstein L., \& Knight, J. (2003). Constitutional Borrowing and Nonborrowing. International Journal of Constitutional Law, 1, 196-223 (2003).

Esquirol, J. L. (1997). The Fictions of Latin American Law (Part I). Utah Law Review. 
Esquirol, J. L. (2003). Continuing Fictions of Latin American Law, Florida Law Review, 55.

Esquirol, J. L. (2008). The Failed Law of Latin America. American Journal of Comparative Law, 56.

Esquirol, J. L. (2009). Writing the Law of Latin America. George Washington International Law Review, 40.

Esquirol, J. L. (2013). Legal Latin Americanism. Yale Human Rights and Development Law Journal, 16, 145-170.

Fierro, H. F., \& López, S. (2006). La educación jurídica en México, un panorama general. Estudios Jurídicos En Homenaje A Marta Morineau: Sistemas Jurídicos Contemporáneos, Derecho Comparado.

Frank, J. (1933). Why Not a Clinical Lawyer-School? University of Pennsylvania Law Review, 81(8), 1932-1933.

Friihling, H. (2000). From Dictatorship to Democracy: Law and Social Change in the Andean Region and the Southern Cone of South America. In M. McClymont, \& S. Golub (Eds.), Many Roads To Justice: The Law-Related Work Of Ford Foundation Grantees Around The World.

Gilbert, J. (2006). Indigenous Peoples' Land Rights under International Law: from victims to actors. Ardsley: Transnational Publishers.

Ginsburg, T., \& Chen, A. H. Y. (2009). Administrative Law and Governance in Asia.

Ginsburg, T., \& Chen, A. H. Y. (2003). Judicial Review in New Democracies: Constitutional Courts in Asian Cases.

Gudynas, E. (2009). La ecología política del giro biocéntrico en la nueva Constitución de Ecuador. Revista Estudios Sociales, 32, 34-47.

Hasebe, Y. (2003). Constitutional Borrowing and Political Theory. International Journal of Constitutional Law, 1, 224-243.

Hernández, A. F. (2003). Globalization and Legal Education in Latin America: Issues for Law and Development in the 21st Century. Penn State International Law Review, 21.

Hirschl, R. (2014). Comparative Matters: The Renaissance of Comparative Constitutional Law. Oxford: Oxford University Press.

Hobbes, T. (2003). Leviatán. Buenos Aires: Editorial Lozada.

Hoecke M. v., \& Warrington, M. (1998) Legal Cultures, Legal Paradigms and Legal Doctrine: Towards a
New Model for Comparative Law. International \& Comparative Law Quarterly, 47, 495-536.

Hoeflich, M. H. (1986). Law and Geometry: Legal Science from Leibniz to Langdell. American Journal of Legal History, 30.

Holmes, O. W. (1897). The Path Of The Law. Harvard Law Review, 10.

Hurtado, L. F. P. (2010). Content, Structure, and Growth of Mexican Legal Education. Journal of Legal Education, 59(4).

Kahn, P. (1999). The Cultural Study Of Law: Reconstructing Legal Scholarship. Chicago: University of Chicago Press.

Kahn, P. (2000). Law and Love: The Trials of King Lear. New Haven: Yale University Press.

Kahn, P. (2008). Sacred Violence: Torture, Terror, and Sovereignty. Ann Arbor: University of Michigan Press.

Kahn, P. (2011). Politicaltheology: Four New Chapters Of Sovereignty. New York: Columbia University Press.

Kelemen R. D., \& E. C. Sibbitt. (2004). The Globalization of American Law. International Organization, 58, 103-136.

Koskenniemi, M. (2001). The Gentle Civilizer of Nations: The Rise and Fall of International Law 1870 1960. Cambridge: Cambridge University Press.

Laing, E. A. (1974). Revolution in Latin American Legal Education: The Colombian Experience. Lawyer Of The Americas, 6.

Langer, M. (2004). From Legal Transplants to Legal Translations: The Globalization of Plea Bargaining and the Americanization Thesis in Criminal Procedure. Harvard International Law Journal, 45(1).

Legrand, P. (1997). The Impossibility of 'Legal Transplants'. Maastricht Journal of European and Comparative Law, 4.

Leiter, B. (2010). Legal Formalism and Legal Realism: What Is the Issue?. Legal Theory, 16(2), 111-133.

Leiter, B. (2013). Why Legal Positivism (Again)?. University of Chicago, Public Law Working Paper No. 442. Disponible en SSRN: http://ssrn.com/abstract $=232301$.

Lemaire, GG. (2001). The Orient in Western Art. Cologne: Könemann, 2001.

Lillis T. M., \& Curry, M. J. (2010). Academic writing in a global context: The politics and practices of publishing in English. London: Routledge. 
Llewellyn, K. (1931). Some Realism about Realism Responding to Dean Pound. Harvard Law Review, 44.

Llewellyn, K. N. (1949). Law and the Social Sciences. Harvard Law Review, 62(8), 1286-1305.

Locke, J. (1991). Dos ensayos sobre el gobierno civil. Buenos Aires: Espasa Calpe.

Macchiavello, A. C. (2008). Una experiencia de reforma curricular: el plan de estudios de Derecho de la Universidad Diego Portales. Derecho y Democracia - 15 Cuadernos Unimetanos, 2, 33-43.

Madrazo, A. (2008). From revelation to creation: the origins of text and doctrine in the civil law tradition. I Mexican Law Review, 1.

Maisel, P. (2008). The Role of U.S. Law Faculty in Developing Countries: Striving for Effective CrossCultural Collaboration. Clinical Law Review, 14.

Mattei, U. (1994). Why the Wind Changed: Intellectual Leadership in Western Law. American Journal of Comparative Law, 42.

Mattei, U. (1997). Three Patterns of Law: Taxonomy and Change in the World's Legal Systems. American Journal of Comparative Law, 45.

Mattei, U. (1998). An Opportunity Not to Be Missed: The Future of Comparative Law in The United States. American Journal of Comparative Law, 48.

Mattei, U. (2003). A Theory of Imperial Law: A Study on U.S. Hegemony and the Latin Resistance. Indiana Journal of Global Legal Studies, 10.

Mcllwain, C. H. (1940). Constitutionalism: Ancient and Modern. Ithaca: Cornell University Press.

Medina, D. L. (2004). Teoria Impura Del Derecho. Bogotá: Editorial Legis.

Mendes, C. H. (2008). La escuela de Derecho de São Paulo de la Fundación Getulio Vargas Caio Farah Rodriguez Joaquim Falcão. Derecho y Democracia - 15 Cuadernos Unimetanos, 16-32.

Merryman, J. H. (1977). Comparative Law and Social Change: On the Origins, Style, Decline, and Revival of the Law and Development Movement. American Journal of Comparative Law, 25, 484-489.

Merryman, J. H., \& Pérez-Perdomo, R. (2007). The Civil Law Tradition: An Introduction To The Legal Systems Of Europe And Latin America. Stanford: Stanford University Press.

Mickelson, K. (2000). South, North, International Environmental Law, and International Environmental Lawyers. Yearbook of International Environ- mental Law, 11.

Mickelson, K. (2009). Beyond a Politics of the Possible? South-North Relations and Climate Justice. Melbourne Journal of International Law, 10, 411423.

Mirow, M. C. (2001). Borrowing Private Law in Latin America: Andres Bello's Use of the "Code Napoleon" in Drafting the Chilean Civil Code. Louisiana Law Review, 61(2), 290-329.

Mirow, M. C. (2004). Latin American Law: A History Of Private Law And Institutions In Spanish America. Austin: University of Texas Press.

Mirow, M. C. (2005). The Code Napoleon: Buried but Ruling in Latin America. Denver Journal of International Law and Policy, 33, 179-194.

Monateri. P. G., \& Samuel, G. (2006). La Invención del Derecho Privado. Bogotá: Universidad de Los Andes.

Morin, FJ., \& Gold, R. (2013). An Integrated Model of Legal Transplantation: The Diffusion of Intellectual Property Law in Developing Countries. Available at SSRN: http://ssrn.com/abstract=2335531

Morris, R. C., \& Spivak, G. C. (2010). Can the Subaltern Speak?: Reflections on the History of an Idea. New York: Columbia University Press.

Murillo, M. V. (2005). Partisanship Amidst Convergence: The Politics of Labor Reform in Latin America. Comparative Politics, 37(4), 44-458.

Mutua, M. W. (2000). What is Twail?. American Society of International Law, Proceedings of the 94th Annual Meeting, 31-39.

Nkrumah, K. (1962). Law in Africa. African Law Journal, 6.

Nolutshungu, S. C. (1993). Constitutionalism in Africa: Some Conclusions. In D. Greenberg, et al. (Eds.) Constitutionalism and Democracy: Transitions in the Contemporary World.

Olea, H. (2013). El Formalismo Jurídico, La Educación Jurídica Y La Práctica Profesional Del Derecho En Latinoamérica. Derecho Y Pueblo Mapuche, Universidad Diego Portales, Chile.

Osiatynski, W. (2003). Paradoxes of Constitutional Borrowing. International Journal of Constitutional Law, 1, 244-268.

Pargendler, M. (2012). The Rise and Decline of Legal Families. American Journal of Comparative Law, 60(4).

Pérez-Perdomo, R. (2005). Rule of Law and Layers in 
Latin America. Annals Of The American Acamedy Of Political And Social Science, 603(1).

Pérez-Perdomo, R. (2011). Legal Education in Late Twentieth-Century Latin America. In L. Friedman, R. Pérez-Perdomo, \& M. Gómez (Eds.), Law In Many Societies (p. 63).

Posner, R. (1973). Economic Analysis Of Law. Boston: Little Brown.

Rawls, J. (1971). A Theory of Justice. Cambridge: Harvard University Press.

Rawls, J. (1996). Liberalismo Político. México: Fondo de Cultura Económica.

Ritttich, K. (2006). The Future of Law and Development: Second-Generation Reforms and the Incorporation of the Social. In D. Trubek and A. Santos (Eds.) The New Law and Economic Development, (pp. 203-352). Cambridge University Press.

Rodriguez, C. F., \& Falcão, J. (2008). O projeto da escola de Direito do Rio de Janeiro da FGV. Derecho y Democracia - 15 Cuadernos Unimetanos, 44-50.

Rosenkrantz, C. F. (2003). Against Borrowings and Other Nonauthoritative Uses of Foreign Law. International Journal of Consitutional Law, 1(2), 26995.

Rosenthal, D. A. (1982). Orientalism: the near east in French painting, 1800-1880. Rochester: Memorial Art Gallery of the University of Rochester.

Roy, A. (2008). Postcolonial Theory and Law: A Critical Introduction. Adelaide Law Review, 29(1/2).

Ruskola, T. (2002). Legal Orientalism, Michigan Law Review, 101(1), 179-234.

Santos, B. S. (1995). Three Metaphors for a New Conception of Law: The Frontier, the Baroque and the South. Law \& Society Review, 29, 569-584.

Scheppele, K. L. (2003). Aspirational and Aversive Constitutionalism: The Case for Studying Crossconstitutional Influence through Negative Models. International Journal of Constitutional Law, 1, 296-324.

Schmidhauser, J. R. (1989). Power, Legal Imperialism, and Dependency. Law \& Society Review. 23(5), 857-878.

Schmidhauser, J. R. (1992). Legal Imperialism: Its Enduring Impact on Colonial and Post-Colonial Judicial Systems. International Political Science, 13(3).

Spamann, H. (2010). Contemporary Legal Transplants - Legal Families and the Diffusion of (Corporate)
Law. Brigham Young University Law Review, (6), 1813-1877.

Spector, H. (2008). The academic study of law in Argentina. Derecho y Democracia - 15 Cuadernos Unimetanos, 6-15.

Steinitz, M. (2009). Internationalized Pro Bono and a New Global Role for Lawyers in the 21st Century: Lessons from Nation Building in Southern Sudan. Yale Human Rights and Development Law Journal, 12, 205-240.

Stevens, M. A. (Ed.) (1984). The Orientalists: Delacroix to Matisse: European Painters in North Africa and the Near East. London: Royal Academy of Arts.

Tamanaha, B. Z. (2009). The Primacy of Society and the Failures of Law and Development. St. John's Univ. Legal Studies Research Paper Series, Paper No. 09-0172. Disponible en: http://papers.ssrn. com/sol3/papers.cfm?abstract_id=1406999

The Association of the Bar of the City of NY. (2002). Report on The Buenos Aires Conference on Pro Bono and Access to Justice, The Committee on InterAmerican Affairs.

Toro, B. L. (2003). Las clínicas jurídicas de interés público en Colombia. Retos y posibilidades de una naciente experiencia. In Clínicas de Interés Público y Enseñanza del Derecho (pp. 9-47).

Torres, A. (2007). From Inquisitorial to Accusatory: Colombia and Guatemala's Legal Transition 2. Law and Justice in the Americas Working Paper Series, Paper no. 4. Disponible en http://lawdigitalcommons.bc.edu/ljawps/4.

Trubek, D. M. (2006). The "Rule of Law" in Development Assistance: Past, Present, and Future. In D. M. Trubek \& A. Santos (Eds.), The New Law And Economic Development: A Critical Appraisal. New York: Cambridge University Press.

Trubek, D. M., \& Santos, A. (2006). Introduction: The Third Moment in Law and Develop- ment Theory and the Emergence of a New Critical Practice. In D. M. Trubek, \& A. Santos (Eds.), The New Law And Economic Development: A Critical Appraisal (pp. 2-3). New York: Cambridge University Press.

Trubek, D., \& Galanter, M. (1974). Scholars in SelfEstrangement: Some Reflectionson on the Crisis in Law and Development Studies. Wisconsin Law Review, 4, 1062-1095.

Tully, J. (1997). Strange multiplicity: Constitucionalism in an Age of Diversity. Cambridge: Cambridge 
University Press.

Tushnet, M. (1999). The Possibilities of Comparative Constitutional Law. Yale Law Journal, 108(6), 1225-1239.

Vargas, J. M. (2008). La reforma a la enseñanza del derecho en la Universidad de Los Andes. Derecho y Democracia - 15 Cuadernos Unimetanos, 63-90.

Vargas, J. M. (2009). Educación jurídica en Latinoamérica: dificultades curriculares para promover los temas de interés público y justicia social. $E l$ Otro Derecho, 38, 29-42.

Vargas, J. M. (2010). The Current State Of Legal Education Reform In Latin America: A Critical Appraisal. Journal of Legal Education, 59.

White, L. E. (2000). Pro Bono or Partnership: Rethinking Lawyers' Public Service Obligations for a New Millennium. Journal of Legal Education, 50, 134-146.

Wiegand, W. (1996). Americanization of Law: Reception or Convergence. In L. M. Friedman, \& H. N. Scheiber (Eds), Legal Culture and the Legal Profession. Boulder: Westview Press.

Wilson, R. J. (2004). Training for Justice: The Global Reach Of Clinical Legal Education. Penn State International Law Review, 22, 421-431.

Data de submissão/Submission date: 12.11.2014

Data de aceitação para publicação/Acceptance date: 12.12.2014 